\title{
Processes of deep-water renewal in Lake Baikal
}

\author{
R. Hohmann, R. Kipfer, F. Peeters, G. Piepke, and D. M. Imboden
}

Swiss Federal Institute of Technology (ETH) and Swiss Federal Institute for Environmental Science and Technology (EAWAG), CH-8600 Dübendorf, Switzerland

\section{N. Shimaraev}

Limnological Institute of the Siberian Division of the Russian Academy of Sciences, Irkutsk 664033, Russia

\begin{abstract}
Deep-water renewal in Lake Baikal (Siberia), the world's deepest lake and largest lake by volume, is relatively fast. Water age calculated from tritium and helium as well as from chlorofluorocarbons does not exceed 19 yr. Relative saturation of dissolved oxygen typically exceeds $80 \%$. The equation of state of Baikal water was determined including the effect.of dissolved ions and silicic acid. Based on nearly 600 CTD profiles taken between 1993 and 1995, two mechanisms of deep-water mixing were identified. (1) In spring, cold and relatively saline water from the Selenga, the major inflow to the lake, forms a density plume that reaches the bottom of the central basin during April and early May. Due to entrainment of lake water the plume transports about $125 \mathrm{~km}^{3}$ of water per year to the decpest part of the basin. Later in spring, the river water forms the thermal bar observed along the eastern shore. There are indications that parts of the Selenga are also plunging to the deep part of the southern basin. (2) At Academician Ridge, separating the cold and "saline" water of the central basin from the warmer and slightly less saline water of the northern basin, horizontal mixing results in a water mass that can sink on either side of the sill. Whereas in the central basin the water mass stays at intermediate depth, in the northern basin it sinks to the decpest part. More detailed data are nocded to quantify this density flux. No indication of a wind-induced thermobaric instability was found.
\end{abstract}

Lake Baikal (Siberia) is the deepest $(1632 \mathrm{~m})$ and largest lake (volume $23,015 \mathrm{~km}^{3}$ ) on earth (Shimaraev et al. 1994). It holds $\sim 20 \%$ of the global fresh liquid surface water. The lake is located in the great Baikal Rift Zone of eastern Siberia. It is divided by underwater sills into three main basins (Fig. 1): the southern basin (max. depth $1,432 \mathrm{~m}$ ), the central basin $(1,632 \mathrm{~m})$, and the northern basin $(897 \mathrm{~m})$. Main inflows are the Selenga, the Upper Angara, and the Barguzin. The only outlet is the Angara.

Despite its great depth, relative saturation of dissolved oxygen exceeds $80 \%$ in the entire water column. Based on the vertical distribution of chlorofluorocarbons (CFCs), Weiss et al. (1991) have shown that the water age is nowhere greater than 16 yr. Water age is defined here as the time since a given water parcel was last exposed at the water surface. Both observations raise the question of how the bottom water is renewed in such a deep lake.

In most lakes, partial or complete turnover of the water

\footnotetext{
Acknowledgments

We thank our colleagues of the Limnological Institute of the Siberian Division of the Russian Academy of Sciences in Irkutsk, especially M. Grachev, and the Baikal International Center of Ecological Rescarch (BICER) for providing ship time and support. Spccial thanks go to Michael Schurter for his reliable technical and experimental work, to T. Khodzher and Laura Sigg for providing chemical data, and to David Liewellyn-Jones for providing satellite images. We also thank N. Granin, A. Zhdanov, and the crew of the RV Vereshchagin. David Livingstone helped to improve the language of the final text. This research was made possible by the financial support of the Swiss Federal Institute of Environmental Science and Technology (EAWAG), the Swiss Federal Institute of Technology (ETH), and the Swiss Federal Office for Science and Education (BBW).
}

column, if it occurs, is caused by the seasonal cooling and heating of the water, often supported by wind forcing. Yet, this mechanism is commonly restricted to the upper few hundred meters. In deeper water bodies, horizontal density gradients are necessary to induce vertical exchange down to the bottom. Often such gradients are produced by a combination of temperature and salinity gradients. The formation of deep water in the North Atlantic is one of the most prominent examples of this (Dickson et al. 1990). In lakes such gradients are often caused by inflows with differing salt concentrations (e.g. Aeschbach-Hertig et al. 1996).

In deep freshwater lakes in which salinity gradients are small, the nonlinearity of the equation of state of water gives rise to two special phenomena. (1) The thermobaric instability is linked to the pressure dependence of the temperature of maximum density $\left(T_{\mathrm{md}}\right)$. It has been proposed by Weiss et al. (1991) as the key process for deep-water formation in Lake Baikal during winter, when the surface water is colder than the deep water. (2) Cabbeling (McDougall 1987b) results from the nonlinear temperature dependence of water density, as a result of which the mixing of water masses of different temperature always lcads to an increase in the mean density. The best known example is the so-called thermal bar, where two adjacent surface water masses, one warmer and the other colder than $4^{\circ} \mathrm{C}$, mix to form water of maximum density that then sinks to greater depth (Imboden and Wüest 1995).

Shimaraev et al. (1993) interpreted the thermal bar that develops in spring along most of the shoreline of Lake Bai$\mathrm{kal}$ as the main trigger of deep-water formation. The authors suggested that the thermobaric instability is initiated by the spring thermal bar at the southeastern shore of the central basin. Deep-water renewal is then accomplished by a jet of 


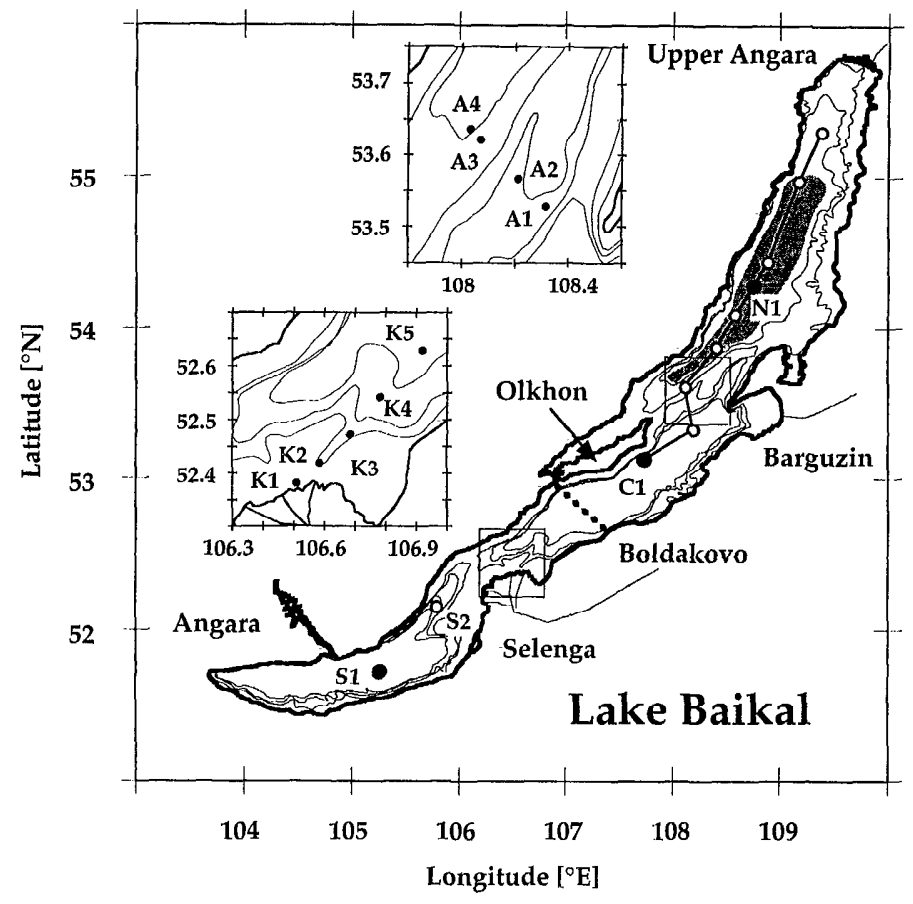

Fig. 1. Map of Lake Baikal showing isobaths at 400-, 700-, and 1,000-m depth. The lake is divided into southern, central, and northern basins: S1, C1, and N1 mark the deepest points of these basins. White circles show the locations of further sampling stations. The cold bottom boundary layer found in spring 1995 in the northern basin is shaded. The Selenga, Upper Angara, and Barguzin are the main inflows, the Angara at the southwestern end of the lake the only outflow. The transect between Olkhon Island and the shore of Boldakovo is marked by small black dots. The insets show the subsurface sills at Academician Ridge and Selenga Delta that separate the three basins. K1-K5 arc sampling stations in the Kukui Canyon cut into the Selenga Delta. Sampling stations across Academician Ridge are labeled A1-A4.

cold water that supposedly originates from the hypolimnion on the open-lake side of the thermal bar. However, it remains unclear how the cold surface water is able to cross the $T_{\text {ind }}$ line and sink to the bottom. Furthermore, the temperature of the bottom water in the central basin is colder than the jet proposed by Shimaraev et al. (1993). In fact, a more detailed analysis of the thermal bar leads to the conclusion that it can only explain vertical mixing in the top $200-300 \mathrm{~m}$ of the water column (Peeters et al. 1996). Because $T_{\text {rud }}$ decreases with depth (pressure) by $\sim 0.2 \mathrm{~K}$ per $100 \mathrm{~m}$, the water at $4^{\circ} \mathrm{C}$ that forms at the thermal bar cannot sink very far before it meets with colder ambient water that, at this depth, is denser.

Walker and Watts (1995) have developed a numerical model to study the intensity and scale of plumes involved in the formation of deep water. Deep convection is assumed to be triggered by a storm surge that forces cold surface water below its compensation depth (where water temperature is equal to the local $T_{\mathrm{mu}}$ ). This phenomenon is simulated by initiating the model calculations with an unstable temperature profile in which the mesothermal temperature maximum (MTM), i.e. the layer in which temperature reaches its maximum and crosses the depth-dependent $T_{\text {md }}$ curve, is located deeper than $500 \mathrm{~m}$. If the initial instability is applied adjacent to a solid boundary, the model simulates vigorous plume motion and the production of a large volume of deep water. Unfortunately, the conditions used for the model calculations, especially the extremely deep MTM, have never been observed in Lake Baikal. Thus, it remains unclear whether the model would succeed in simulating a sinking plume containing water that is really cold enough to explain the observed temperature decrease in the deep water of the central basin using more realistic initial conditions.

Killworth et al. (1996) use a two-dimensional model to show that wind forcing is a possible trigger for deep convection. By continuously applying a sinusoidal wind stress to the entire lake surface with a random stress added, complete overturning of the water column is achieved. The authors then use an inverse 1/1/2-dimensional filling-box model to calculate annually averaged fluxes by assuming the observed distribution of tracers to be stationary (oxygen) or to have a stationary relative vertical structure (CFCs). The vertical fluxes calculated from the model decrease with depth. This could result from wind-induced mixing but is also consistent with the concept of a river plume that, depending on its temperature, sinks to different depths. At a fixed depth, the calculated fluxes vary by a factor of up to two between the different basins, suggesting that the process of deep-water renewal is different in each basin.

There is a basic difficulty linked to the process of thermobaric instability proposed by Weiss et al. (1991) and Killworth et al. (1996). Because water temperature near the bottom of the central basin drops to $\sim 3.1^{\circ} \mathrm{C}$, the MTM would have to be pushed downward by $\sim 350 \mathrm{~m}$ to cause water of $3.1^{\circ} \mathrm{C}$ to sink from the surface to the lake bottom. Although wind shear cannot be specifically excluded, several hundred CTD profiles taken during different times of the year have only rarely shown thermocline displacements of more than just one-fourth of the required distance. For instance, measurements before and after a severe storm in November 1994 with wind velocities $>20 \mathrm{~m} \mathrm{~s}^{-1}$ document a temporary downward displacement of the thermocline by just $\sim 80 \mathrm{~m}$.

Because salinity variations are extremely small in Lake Baikal (Falkner et al. 1991), the influence of dissolved chemicals on water density has been neglected by all authors. However, the thermal expansion coefficient is very small in the region of the MTM, and even small salinity differences may become dominant for the vertical density structure. Thus, deep-water renewal is likely to occur in regions where water masses of different salinity meet. Such a location is found at Academician Ridge, where fresh water from the northern basin mixes with slightly more saline water from the central basin. Because some of the inflows have a greater salinity than the lake, the river mouths, e.g. the Selenga Delta, are other areas of potential deep-water formation.

Based on a thorough theoretical analysis of stability and neutrally buoyant transport in lakes (Peeters et al. 1996) and on a rather detailed set of data collected during several expeditions to Lake Baikal between 1993 and 1995, we are able to (1) confirm from tritium/helium water ages (Hohmann et al. in press) the order of magnitude of deep-water exchange given by Weiss et al. (1991), and (2) present a 
more consistent picture of the processes that cause the exchange of deep water. The latter point will be addressed here.

\section{Methods}

The study described here is based on high-resolution CTD profiles taken during several cruises on Lake Baikal, complemented by chemical analyses of water samples. This information is used to calculate one- and two-dimensional distributions of water density that are then analyzed in terms of gravitational instabilities and the potential for the formation of density-induced currents. There are three steps involved in this procedure: (1) calculation of salinity $S$ from electric conductivity and chemical water analysis; (2) calculation of the salinity effect on water density (the coefficient of haline contraction) for the specific chemical composition of Lake Baikal water; and (3) evaluation of the calculated density field with respect to gravitational flow and mixing.

Calculation of salinity from conductivity-Salinity $S$ is defined as the total mass of dissolved solids per unit mass of solute. In principle, a water sample should be analyzed for all its major components and its salinity $S\left(\mathrm{~g} \mathrm{~kg}^{-1}\right)$ calculated as follows:

$$
S=\frac{1}{\rho} \sum_{i} M_{i} c_{i},
$$

where $\rho$ is water density $\left(\mathrm{kg} \mathrm{m}^{3}\right), M_{i}$ the molar mass ( $\mathrm{g}$ $\left.\mathrm{mol}^{-1}\right)$, and $c_{i}$ the molar concentration $\left(\mathrm{mol} \mathrm{m}^{-3}\right)$ of species $i$. If the relative composition of the water is constant, $S$ can be calculated from the electrical conductivity $\kappa$. However, depending on the chemical composition of the water, each lake has its own specific $\kappa: S$ ratio that can be derived from basic physicochemical properties of the dissolved ions as described by Wiiest et al. (1996).

First, the conductivity measured at temperature $T$ and pressure $p, \kappa_{T}{ }^{p}$, is normalized to standard pressure:

$$
\kappa_{T}^{0}=\kappa_{T}^{p}\left[1+\delta(T)_{p}\right]^{-1},
$$

where $\kappa_{T}^{0}\left(\mu \mathrm{S} \mathrm{cm}^{-1}\right)$ is the conductivity at atmospheric pressure (conventionally defined as $p=0$ ). The specific pressure correction $\delta(T)$ accounts for the increase in ionic conductivity due to compression. Because no data are available for freshwater, Wuiest et al. (1996) linearly extrapolated the seawater data of Bradshaw and Schleicher (1965) to zero salinity. Their eq. $4 \mathrm{~d}$ applied to $T=3.5^{\circ} \mathrm{C}$ (a typical value for the deep water of Lake Baikal) yields $\delta\left(3.5^{\circ} \mathrm{C}\right)=1.669 \times$ $10^{-5} \mathrm{dbar}^{-1}$. To check this value we took vertical CTD profiles with the conductivity and temperature sensors wrapped in a plastic bag to prevent water exchange with the surrounding water. Temperature within the bag was approximately constant $\left(\theta \approx 3.5 \pm 0.02^{\circ} \mathrm{C}\right)$. The experiment yielded $\delta_{\text {cxp }}\left(3.5^{\circ} \mathrm{C}\right)=1.556 \times 10^{-5} \mathrm{dbar}^{-1}$. The correspondence between the extrapolated and the experimental value is remarkable. We prefer the latter value because it includes the possible instrument-specific effect of pressure on the conductivity sensor. In fact, it appears that the temperature dependence of $\delta(T)$ is not relevant for the range encountered in Lake Baikal.
Table 1. Typical ionic concentrations $c_{i}$ and conductivity in Lake Baikal water

\begin{tabular}{lccccc}
\hline \hline & $\begin{array}{c}c_{i}^{*} \\
\left(\mathrm{mmol} \mathrm{kg}^{*-1}\right)\end{array}$ & $Z_{i}$ & $\begin{array}{c}\lambda_{20, i}^{\infty} \\
\left(\mathrm{mS} \mathrm{cm}^{-1}\right. \\
\left.[\mathrm{eq} \mathrm{liter}]^{-1}\right)\end{array}$ & $\begin{array}{c}F_{i} \neq \\
(-)\end{array}$ & $\begin{array}{c}\kappa_{20, i} \S \\
\left(\mu \mathrm{S} \mathrm{cm}{ }^{~}\right)\end{array}$ \\
\hline $\mathrm{HCO}_{3}{ }^{-}$ & $1.0921 \|$ & 1 & 40.29 & 0.97 & 42.69 \\
$\mathrm{CO}^{2}$ & $0.0005 \|$ & 2 & 63.18 & 0.93 & 0.05 \\
$\mathrm{Cl}^{-}$ & 0.0123 & 1 & 68.81 & 0.98 & 0.83 \\
$\mathrm{SO}_{4}{ }^{2-}$ & 0.0574 & 2 & 71.86 & 0.93 & 7.71 \\
$\mathrm{Na}^{+}$ & 0.1550 & 1 & 44.80 & 0.97 & 6.76 \\
$\mathrm{~K}^{+}$ & 0.0241 & 1 & 66.52 & 0.98 & 1.57 \\
$\mathrm{Ca}^{2+}$ & 0.4020 & 2 & 53.04 & 0.92 & 39.42 \\
$\mathrm{Mg}^{2+}$ & 0.1260 & 2 & 47.00 & 0.92 & 10.89 \\
& & & & & $\Sigma=109.91$ \\
\hline
\end{tabular}

* Concentrations from Falkner st al. (1991).

$\dagger$ Equivalent conductance $\lambda_{20, i}^{\times}$at $T=20^{\circ} \mathrm{C}$ and infinite dilution. For details, sce Wücst et al. (1996).

$¥$ Reduction coefficient $F_{i}$. For details, sec Wüest et al. (1996).

$\S$ Conductivity of ionic species $i$ at $T=20^{\circ} \mathrm{C}, \kappa_{20, i}=\rho \cdot F_{i} \cdot \lambda_{20, i}^{c} \cdot Z_{i} \cdot c_{i}(\mu \mathrm{S} / \mathrm{cm})$, with $\rho=$ density of water and $Z_{i}=$ ionic charge.

$\|$ Calculated from alkalinity $=1.093 \mathrm{~mol} / \mathrm{kg}, \mathrm{pH} 7.2$ (Falkner et al. 1991) and $T=3.5^{\circ} \mathrm{C}$.

Second, the reference conductivity at $T=20^{\circ} \mathrm{C}, \kappa_{20}{ }^{\circ}$, is calculated as follows:

$$
\kappa_{20}{ }^{0}=\kappa_{T}^{0}\left(f_{T}\right)^{-1} .
$$

The polynomial $f_{T}$ is determined from the specific ionic composition of Baikal water measured by Falkner et al. (1991) and the temperature dependence of the equivalent conductance of the major ions (Table 1: see Wuiest et al. [1996] for details). For Baikal water:

$$
\begin{aligned}
f_{T}= & 0.59911+1.6899 \times 10^{-2} \times T \\
& +1.9024 \times 10^{-4} \times T^{2}-1.6495 \times 10^{-6} \times T^{3}
\end{aligned}
$$

with $T$ in ${ }^{\circ} \mathrm{C}$.

Finally, the salinity due to the ionic composition of the water, $S_{c}$, follows from $\kappa_{20}{ }^{0}$ by applying

$$
S_{c}=g_{S} \kappa_{20}{ }^{0},
$$

where $g_{s}$ is calculated from the equivalent conductance of the major ions. Because the ionic conductance decreases with the ionic strength of the solution, $g_{s}$ increases with salinity, i.e. with electric conductivity. For Baikal water it can be approximated by the polynomial

$$
\begin{aligned}
g_{S}= & 8.4456 \times 10^{-4}+3.2654 \times 10^{-7} \times \kappa_{20}{ }^{0} \\
& -4.3774 \times 10^{-10} \times\left(\kappa_{20}{ }^{0}\right)^{2}
\end{aligned}
$$

with $\kappa_{20}{ }^{0}$ in $\mu \mathrm{S} \mathrm{cm}^{-1}$.

The notation $S_{c}$ was introduced in Eq. 5 to distinguish it from the nonionic salinity $S_{0}$. Among all the chemicals that are subsumed under $S_{0}$, in the context of this investigation only $\mathrm{Si}(\mathrm{OH})_{4}$ contributes significantly to the spatial variation of water density. The corresponding salinity is therefore called $S_{\mathrm{S} \text {. }}$. Total salinity $S$ is then defined by

$$
S=S_{c}+S_{\mathrm{Si}} \text {. }
$$


Coefficients of haline contraction and equation of stateThe coefficients of haline contraction for the ionic species and for silica, $\beta_{c}$ and $\beta_{\mathrm{Si}}$ respectively, are defined by:

$$
\begin{aligned}
& \beta_{c}=\frac{1}{\rho} \frac{\partial \rho}{\partial S_{c}} ; \\
& \beta_{\mathrm{Si}}=\frac{1}{\rho} \frac{\partial \rho}{\partial S_{\mathrm{Si}}} .
\end{aligned}
$$

These coefficients can be calculated for standard conditions (atmospheric pressure $p=0, T=25^{\circ} \mathrm{C}$ ) from the partial volumes of the dissolved solids and the specific chemical composition of the water (Wüest et al. 1996). For Baikal water:

$$
\begin{aligned}
& \beta_{c}\left(T=25^{\circ} \mathrm{C}, p=0\right)=0.8107 \times 10^{3} \quad\left(\mathrm{~g} \mathrm{~kg}^{-1}\right)^{-1} ; \\
& \beta_{\mathrm{Si}}\left(T=25^{\circ} \mathrm{C}, p=0\right)=0.36 \times 10^{3} \quad\left(\mathrm{~g} \mathrm{~kg}^{-1}\right)^{-1} .
\end{aligned}
$$

To calculate the coefficients for arbitrary $T$ and $p$, we assume that the temperature and pressure dependence of $\boldsymbol{\beta}_{c}$ and $\beta_{\mathrm{Si}}$ are proportional to the corresponding variation in the coefficient of haline contraction for seawater, $\beta_{\mathrm{CM}}$, calculated from the equation of state by Chen and Millero (1986): $\beta_{c}(T$, $S, p)=1.074 \times \beta_{\mathrm{CM}}(T, S, p) ; \beta_{\mathrm{Si}}(T, S, p)=0.477 \times \beta_{\mathrm{CM}}$ $(T, S, p)$. The full equation of state for Baikal water $\rho\left(T, S_{c}\right.$, $\left.S_{S i}, p\right)$ can now be calculated by integration. Because the functions in the following integrals are nearly constant, they can be approximated by simple multiplication. Thus,

$$
\begin{aligned}
\rho(T, S, p) \equiv & \rho\left(T, S_{c}, S_{\mathrm{Si}}, p\right) \\
= & \rho_{\mathrm{CM}}(T, S=0, p)+\int_{0}^{S_{c}} \frac{\partial \rho\left(T, S_{c}^{\prime}, p\right)}{\partial S_{c}^{\prime}} \mathrm{d} S_{c}^{\prime} \\
& +\int_{0}^{S_{\mathrm{Si}}} \frac{\partial \rho\left(T, S_{\mathrm{Si}}^{\prime}, p\right)}{\partial S_{\mathrm{Si}}^{\prime}} \mathrm{d} S_{\mathrm{Si}}^{\prime} \\
= & \rho_{\mathrm{CM}}(T, 0, p)+\rho_{\mathrm{CM}}\left(T, \frac{S}{2}, p\right) \\
& \times\left[\beta_{c}\left(T, \frac{S}{2}, p\right) S_{c}+\beta_{\mathrm{Si}}\left(T, \frac{S}{2}, p\right) S_{\mathrm{Si}}\right] .
\end{aligned}
$$

For the whole limnological range $\left(0^{\circ} \mathrm{C} \leq T \leq 30^{\circ} \mathrm{C} ; 0 \mathrm{mg} / \mathrm{kg}\right.$ $\leq S \leq 600 \mathrm{mg} / \mathrm{kg}$; 0 bar $\leq p \leq 180$ bar) the values calculated using Eq. 10 and those calculated using the polynomial by Chen and Millero (1986) agree to within eight significant figures. For the range found in Lake Baikal the values match within 10 significant figures.

Water density and stability of the water column-A profound description of the theoretical concepts underlying the calculation of stability from water density is given by Peeters et al. (1996). Equations from this publication are cited as PE followed by the equation number.

The equation of state can be formulated in terms of in situ values of salinity $S$, pressure $p$, and either water temperature $T$ or potential temperature $\theta$ (PE 7):

$$
\hat{\rho}(\theta, S, p)=\rho(T, S, p),
$$

where ^ denotes a function of $\theta, S$, and $p$.

Variations in density due to temperature are described by the coefficient of thermal expansion, $\alpha(T, S, p)$ or $\hat{\alpha}(\theta, S, p)$ (see Gill [1982] and PE 9, 10). In freshwater at atmospheric pressure, maximum density is reached at $3.98^{\circ} \mathrm{C}$. The temperature of maximum density $T_{\text {md }}$, at which both $\alpha(T, S, p)$ and $\hat{\alpha}(\theta, S, p)$ pass through zero and change sign, decreases with increasing pressure at a rate of $-0.021 \mathrm{~K} \mathrm{bar}^{-1}$. The effect of pressure on $\hat{\alpha}(\theta, S, p)$ for different temperatures and $S=0.1 \mathrm{~g} \mathrm{~kg}^{-1}$ is shown in table 1 of Peeters et al. (1996).

The stability of a water column is determined by the vertical variation in water density. Usually, local stability (the stability with respect to an infinitesimal vertical displacement of a water parcel) is described by the Brunt-Väisälä frequency (Gill 1982, PE 16), which, for the case of Lake Baikal, is supplemented by a term describing the effect of silicic acid ( $z$ is positive upward):

$$
\hat{N}_{z}^{2}(\theta, S, p)=g\left(\hat{\alpha} \frac{\mathrm{d} \theta}{\mathrm{d} z}-\hat{\beta}_{c} \frac{\mathrm{d} S_{c}}{\mathrm{~d} z}-\hat{\beta}_{\mathrm{Si}} \frac{\mathrm{d} S_{\mathrm{Si}}}{\mathrm{d} z}\right) .
$$

In order to assess stability over a finite depth interval, oceanographers use potential density to account for the effect of adiabatic temperature changes due to decompression. This concept can be misleading if the adiabatic transport of a water parcel occurs in the vicinity of $T_{\text {md }}$, especially if $\alpha$ changes sign, which is likely to occur in a deep, cold, freshwater lake (see fig. 2 and table 1 of Peeters et al. [1997]). The quasi-density $\rho_{\text {чал }}$ is introduced as an alternative concept (PE 23, 24). The vertical gradient of $\rho_{\text {qua }}$ is proportional to the Brunt-Väisälä frequency at all depths (while for potential density this is only true at the reference depth). In a stable water column, $\rho_{\text {qu }}$ must increase monotonically with depth.

The difference between the ambient in situ density and the density of a given water parcel that is isentropically moved to different depths (PE 30),

$$
\Delta \hat{\rho}(z)=\hat{\rho}(z)-\hat{\rho}_{p a}(z),
$$

can be used to evaluate the depth to which the fluid parcel can sink or rise from its initial position if no mixing between the parcel and its environment occurs. Here $\hat{\rho}_{p a}(z)=\hat{\rho}\left(\theta_{p a}\right.$, $\left.S_{p a}, p[z]\right)$ is the density of the parcel with constant potential temperature $\theta_{p a}$ and salinity $S_{p a}$ but variable pressure $p(z)$, and $\hat{\rho}(z)$ is the in situ density of the ambient water.

For the case of a two- or three-dimensional $\theta, S$ field, McDougall (1984, 1987a) introduces the neutral surface, along which infinitesimal displacements are neutrally buoyant. Over finite distances, however, a water parcel moves off the neutral surface. In contrast, the neutral track is defined (in PE 32) as the path along which a fluid parcel moves buoyancy-free over a finite distance from its equilibrium position. Because the transport along the track is considered to be isentropic, $\theta_{p u}$ and $S_{p a}$ remain constant, i.e. mixing with the surrounding water is excluded. Along the neutral track the density of the parcel is always equal to the local density of the surrounding water (PE 29), and thus the neutral track of a given water parcel is defined by $\Delta \hat{\rho}(z)=0$. Note that every water parcel has its own individual neutral track. 
Table 2. Polynomials to approximate the basin-specific mean vertical concentration of silicic acid. $\mathrm{Si}(\mathrm{OH})_{4}$ concentration in the top $300 \mathrm{~m}$ is approximated by a constant value for the whole lake ( $h=$ distance from water surface).

\begin{tabular}{clccc}
\hline \hline & $\begin{array}{c}\mathrm{Si}(\mathrm{OH})_{4}=a h^{2}+ \\
h(\mathrm{~m}) \\
b h+c\left(\mathrm{mg} \mathrm{liter}{ }^{-1}\right)\end{array}$ & \multicolumn{1}{c}{$a$} & $b$ & $c$ \\
\hline $0-300$ & All basins & & & 3.08 \\
$>300$ & Southern Basin & $1.81 \times 10^{-6}$ & $-1.08 \times 10^{-3}$ & 3.24 \\
& Central Basin & $1.89 \times 10^{-6}$ & $-1.13 \times 10^{-3}$ & 3.25 \\
& Northern Basin & $4.02 \times 10^{-6}$ & $-2.41 \times 10^{-3}$ & 3.44 \\
\hline
\end{tabular}

\section{Field data}

The data presented here were collected during three cruises on Lake Baikal (18 May-26 June 1993; 21 October-14 November 1994; 11 May-4 June 1995) that were organised by the Baikal International Centre for Ecological Research (BICER). A total of 581 CTD casts (198 in 1993, 126 in 1994, 257 in 1995) were taken from aboard the research vessel RV Vereshchagin. Water samples for the analysis of tritium, helium isotopes, and other noble gases were collected during all three expeditions. These results are discussed in Hohmann et al. (in press).

Temperature, conductivity, and pressure (depth) were recorded in situ with an SBE-9 on-line CTD probe from Seabird Electronics. The probe provides a resolution of 0.025 dbar for pressure, $0.0003 \mathrm{~K}$ for temperature, $0.01 \mu \mathrm{S} \mathrm{cm}^{-1}$ for conductivity, and $0.01 \mathrm{mg}$ liter $^{-1}$ for oxygen. Oxygen concentrations were calibrated using Winkler titration data (T. Khodhzer unpubl. data). The probe was also equipped with a transmissometer (Sea Tcch, path length $10 \mathrm{~cm}$ in 1993; Chelsea Instruments, path length $25 \mathrm{~cm}$ in 1994/1995). Light transmission was not calibrated for absolute suspended particle concentration; it is used here only as a qualitative tracer, e.g. for river water.

Ionic salinity $S_{c}$ was detcrmined from electrical conductivity according to the procedure described above. Compared to $S_{c}$ the precision and spatial resolution of silicic acid concentrations measured by T. Khodzher (unpubl. data from 1993 ) is modest. Thus, a mean $S_{\mathrm{Si}}$ distribution was con- structed by assuming a constant value in the surface layer (Weiss et al. 1991; Killworth et al. 1996) determined as the mean value of $>450$ samples. Below $300 \mathrm{~m}$ the concentration of $\mathrm{Si}(\mathrm{OH})_{4}$ increases with depth. For each basin the vertical profile is approximated by a second-order polynomial (Table 2).

Density stratification in Lake Baikal.-Potential temperature (in the following, referred to simply as temperature) and water density were calculated from the CTD data and the vertical distribution of silicic acid. The distribution of silicic acid in the years 1994/1995 was assumed to be the same as in 1993.

In Fig. 2A temperature profiles taken at the deepest part of each basin in spring 1995 are shown. All profiles show inverse stratification with respect to temperature in the top $200 \mathrm{~m}$ of the water column. The MTM is located at $180 \mathrm{~m}$ in the northern basin (temperature at MTM, $T_{\mathrm{mm}}=3.59^{\circ} \mathrm{C}$ ), at $200 \mathrm{~m}$ in the central basin $\left(T_{\mathrm{mm}}=3.56^{\circ} \mathrm{C}\right)$, and at $195 \mathrm{~m}$ in the southern basin $\left(T_{\mathrm{mm}}=3.59^{\circ} \mathrm{C}\right)$. Below the MTM, temperature decreases steadily. In the deepest $20-50 \mathrm{~m}$ of the central basin, temperature decreases by $0.05-0.1^{\circ} \mathrm{C}$. As shown below, such bottom layers were also found in the other basins.

Ionic salinity $\left(S_{c}\right)$ is low and varies by $<1 \mathrm{mg} \mathrm{kg}^{-1}$ within the water column and between the basins (Fig. 2B). The salinity signal measured in the central basin seems to be disturbed by intrusions. The destabilizing effect of the slight decrease in $S_{c}$ with depth in the interior of the southern and central basins is small and compensated for by the gradient of $\theta$ (Fig. 2A). Salinity in the northern basin is significantly smaller and increases with depth.

The steady increase in quasi-density with depth in all three basins (Fig. 2D) illustrates that the combined effects of temperature, salinity, and silicic acid yield a stable stratification. The thermocline at $\sim 100$-m depth marks the zone of maximum stability, i.e. the zone with the largest gradient of $\hat{\rho}_{\text {qua }}$. This gradient is small near the MTM, indicating that the stratification is weak. A pronounced increase in $\hat{\rho}_{\text {qua }}$ at the bottom of the central and northern basins points to stably stratified boundary layers.
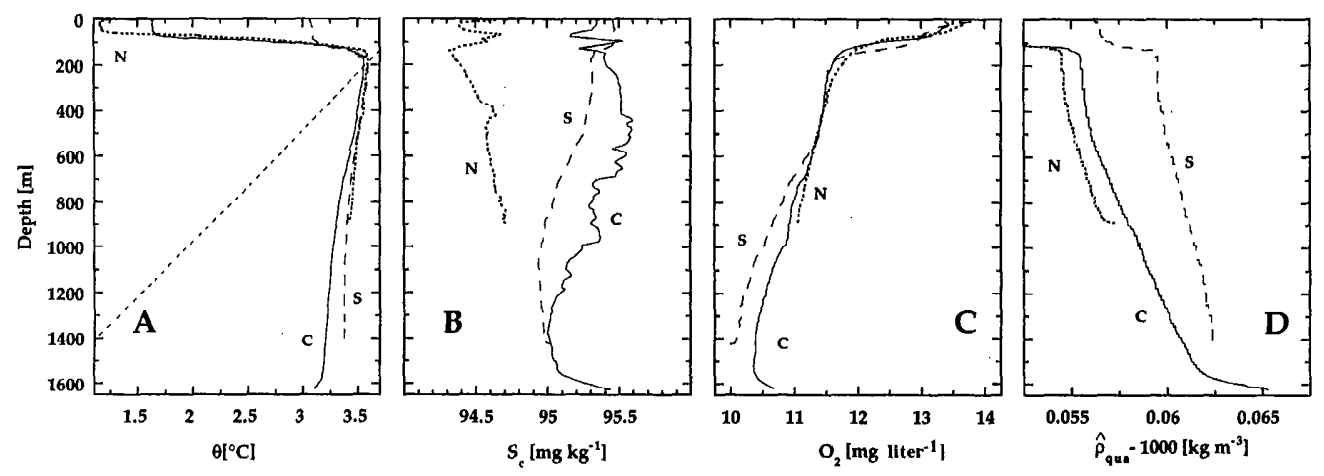

Fig. 2. (A) Potential temperature $\theta$, (B) ionic salinity $S_{c}$, (C) dissolved oxygen concentration $\left[\mathrm{O}_{2}\right]$, and (D) quasi-density $\hat{\rho}_{\text {qua }}$ at the deepest point of the southern basin (- - ), the Central Basin (-), and the Northern Basin (…....) measurcd between 28 May and 1 June 1995. The straight dashed line shown in panel $\mathrm{A}$ is the temperature of maximum density, $T_{\mathrm{md}}$. 


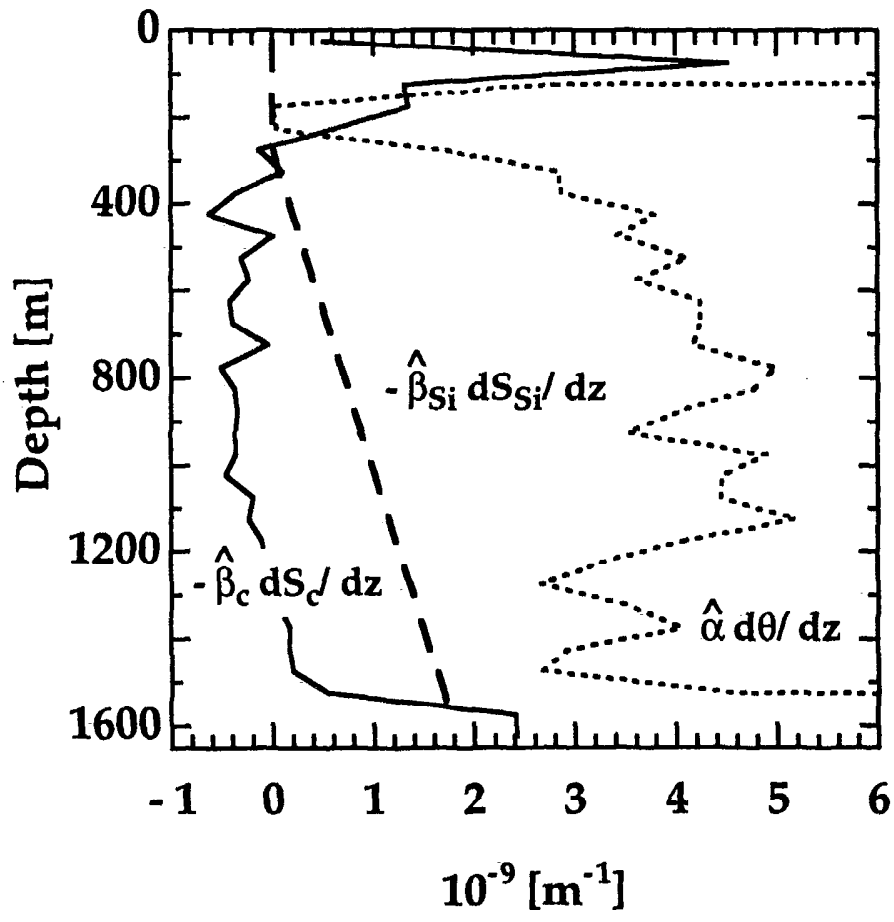

Fig. 3. Impact of potential temperature $\theta(\cdots . . .$.$) , ionic salinity$ $S_{c}(-)$, and silicic acid $S_{\mathrm{Si}}(--)$ on local vertical stability calculated from $\mathrm{Eq} .12$ for the profile in the central basin shown in Fig. 2. The figure is drawn such that positive values correspond to positive stability. Note that the difference between $\hat{\beta}$ and $\beta$ is extremely small.

The contribution of $\theta, S_{c}$ and $S_{\mathrm{Si}}$ to the local vertical stability (Eq. 12) is shown in Fig. 3. Stability is dominated by the temperature stratification $(\hat{\alpha} \times \partial \theta / \partial z)$, cxcept near the MTM, where temperature crosses the $T_{\mathrm{nul}}$ curve and $\hat{\alpha}$ becomes zero. The contribution of dissolved ions to vertical

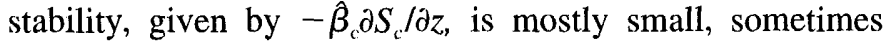
even negative, except in the top $300 \mathrm{~m}$ and in the bottom boundary layer. The contribution of silicic acid to vertical stability, given by $-\hat{\beta}_{\mathrm{Si}} \partial S_{\mathrm{Si}} / \partial z$, is positive and of intermediate size. Note that the approximation of $\mathrm{Si}(\mathrm{OH})_{4}$ by an average profile (see Table 2) makes this term rather smooth.

Signals in the bottom water-In all three basins, distinct temperature and salinity signals in the bottom layer were observed, although at different times and of different kind (Fig. 4). These signals may help to identify the processes responsible for deep-water renewal and the origin of the water that is mixed to the bottom of the lake.

Temperature and salinity changes in both directions were observed in the bottom layer of the southern basin (Fig. 4A, B). In contrast to the other basins, the signals in the southern basin are restricted to the lowermost 3-5 $\mathrm{m}$ of the water column. A cooling event occurred between 1 June and 26 June 1993 that led to a temperature drop of $0.01 \mathrm{~K}$ and a slight increase in the oxygen concentration but left salinity virtually unchanged. In contrast, the first profiles taken during the cruise of spring 1995 revealed a distinct increase in temperature and salinity as well as a slight decrease in ox- ygen concentration and light transmission in the bottom layer. The temperature increase from $3.375^{\circ} \mathrm{C}$ to $3.385^{\circ} \mathrm{C}$ causes a density change of $-0.35 \mathrm{~g} \mathrm{~m}^{-3}\left(\hat{\alpha} \approx 35 \times 10^{-6} \mathrm{~K}^{-1}\right)$, which is partially balanced by a change in salinity from 95 to $95.2 \mathrm{mg} \mathrm{kg}{ }^{-1}$, causing a density change of $+0.16 \mathrm{~g} \mathrm{~m}^{-3}$ $\left(\beta_{c}=0.81 \times 10^{-6} \mathrm{mg} \mathrm{kg}^{-1}\right)$. The background field of silicic acid causes a small density increase of $0.03 \mathrm{~g} \mathrm{~m}^{-3}$. Assuming a stable stratification, the remaining difference must be balanced by an additional increase in the concentration of $\mathrm{Si}(\mathrm{OH})_{4}$ and(or) suspended particles. In fact, light transmission drops from 79.6 to $78.9 \%$ in the lowermost $20 \mathrm{~m}$, indicating that the bottom layer is enriched with particles.

In the central basin (Figs. 4C, D), the bottom layer always consists of cold, higher salinity water enriched in oxygen and has a lower light transmission than the bulk water above. The signals were rather similar in spring 1993 and 1995 but less pronounced in fall 1994.

Both increases and decreases in temperature and salinity were observed in the bottom layer of the northern basin (Fig. $4 \mathrm{E}, \mathrm{F})$. A dramatic cooling of the bottom water was registered between 25 May and 19 June 1993 ( $25 \mathrm{~d}$ ), when temperature in the lowermost $20 \mathrm{~m}$ dropped by more than 0.1 $\mathrm{K}$, salinity decreased by about $0.2 \mathrm{mg} \mathrm{kg}^{-1}$, and the oxygen concentration increased by $\sim 0.5 \mathrm{mg} \mathrm{liter}^{-1}$. On 7 November 1994, the measurements revealed a pronounced bottom layer with a homogeneous salinity excess, yet no signal in either temperature or oxygen was seen. On 24 May 1995, another cold bottom layer was detected.

\section{Discussion}

The temperature decrease with depth below the MTM implies that large-scale convective mixing, and not merely diffusion, must be involved in the formation of deep water. The supply of cold water must be sufficient to balance the turbulent vertical flux of heat as well as geothermal heating. Nowhere below the MTM is the water cold enough to be able to cool the deep water to the extent observed in the central basin (Fig. 2A). Thus, the cold signal measured in the bottom layer of this basin must be generated either by cold water from above the MTM during winter, or by cold inflows. Because the adjacent basins are warmer, the cold bottom layers in the southern and northern basins could, among other possibilities, originate from the central basin. Furthermore, the warm signals found in the northern basin, and also occasionally in the southern basin, could be produced by geothermal heating (Golubev et al. 1993), by subaquatic hydrothermal springs (Kipfer et al. 1993, 1996), or by entrainment of warmer water from the surface.

A detailed analysis of the depth and the temperature of the MTM reveals two potential regions of deep-water formation: (1) the Selenga Delta between the southern and the central basin; and (2) Academician Ridge, which separates the central from the northern basin. Fig. 5 shows the twodimensional $\left(\theta, S_{c}\right)$-distribution obtained from a transect along the thalweg (the deepest possible path along the major axis) from the northern to the southern end of the lake recorded between 17 June and 26 June 1993. There are several notable features. In the region of both sills, the bottom water 

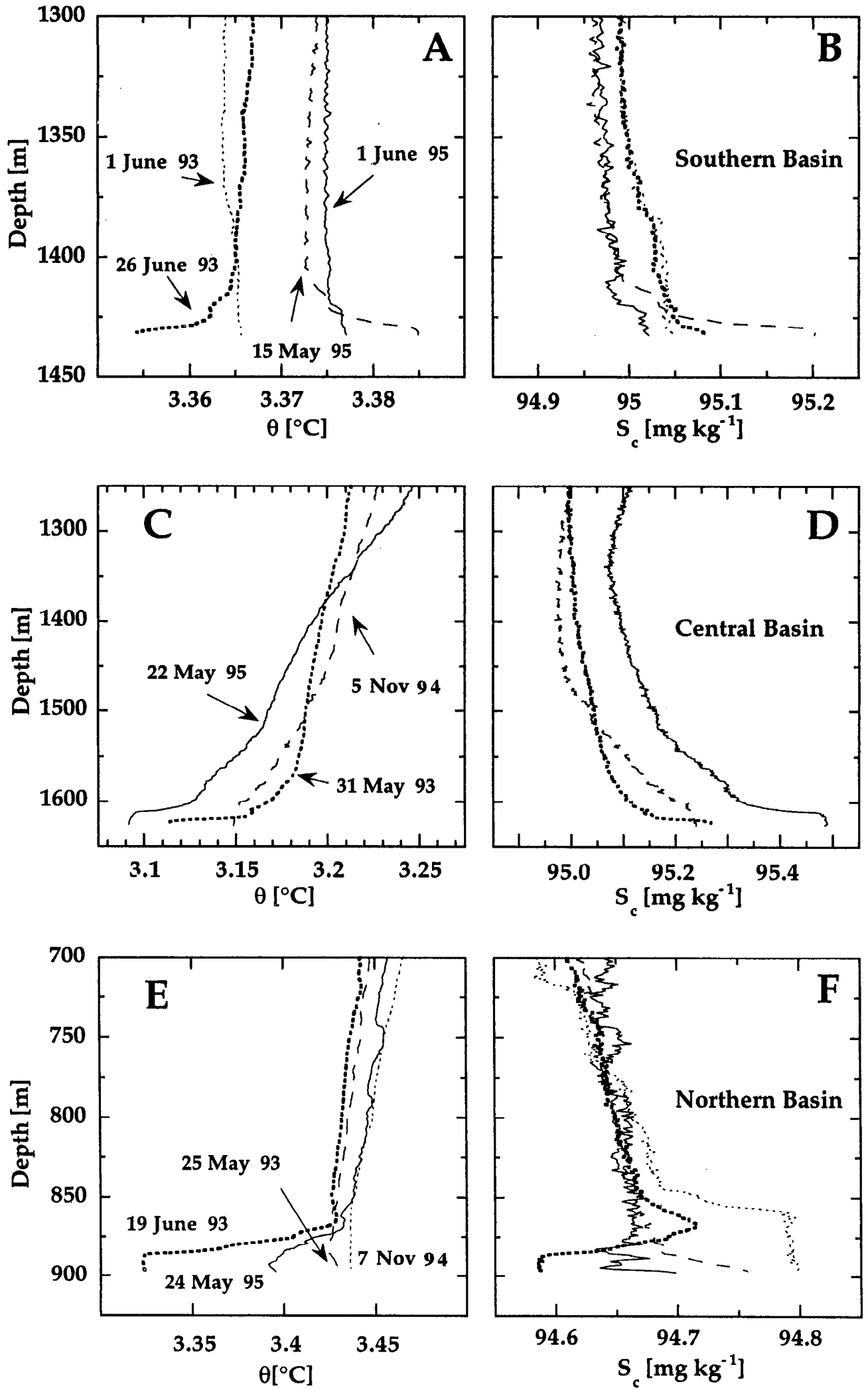

Fig. 4. The evolution of bottom boundary layers in the three major basins of Lake Baikal traced by potential temperature $\theta$ and ionic salinity $S_{c}(\mathrm{~A}, \mathrm{~B})$ In the southern basin, formation of a cold bottom layer with virtually unchanged salinity was observed in June 1993, while on 15 May 1995 a warm, saline layer was formed that had disappeared by 1 June. (C,D) In the central basin a cold and saline bottom layer was found at all times. (E,F) In the northern basin bottom layers were cold while salinity changed in either direction. 

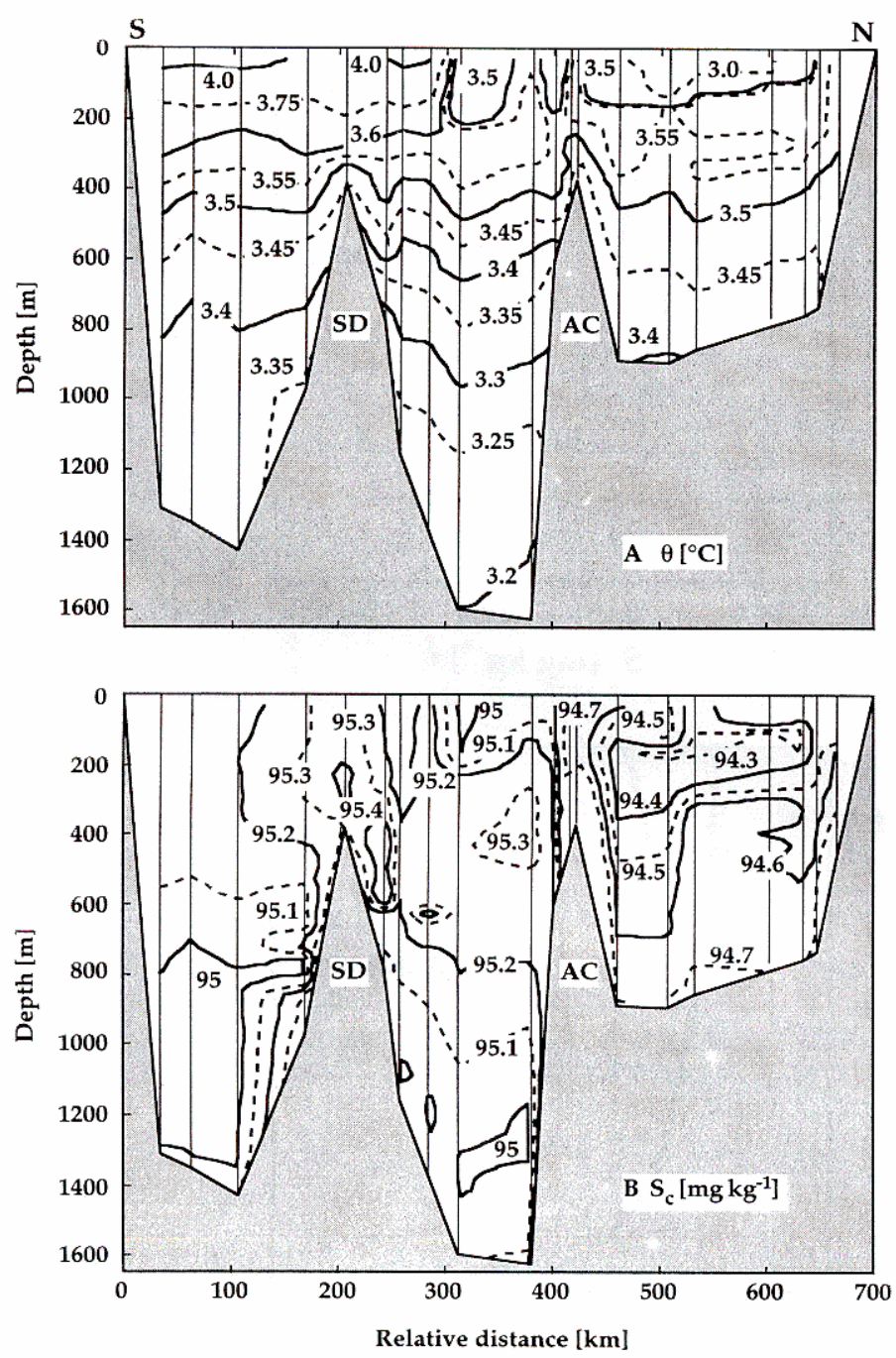

Fig. 5. Two-dimensional isopleths of (A) potential temperature $\theta$ and (B) ionic salinity $S_{c}$ measured along the thalweg from north (right) to south (left) on 17-26 June 1993. SD = Selenga Delta; $\mathrm{AC}=$ Academician Ridge.

is significantly colder than in the open lake at the same depth. Water near the Selenga Delta has a larger salinity than water in the southern and the central basin. Cold and saline water seems to plunge to the deep part of the lake on either side of the delta. At Academician Ridge the salinity difference between the central and the northern basin causes the isohalines to become vertical. Saline water seems to sink from the central basin to the deep part of the northern basin. In the following discussion the situations at both locations are analyzed in more detail.

Selenga River-The Selenga is the major inflow to Lake Baikal. Its rather large delta is located at the sill between the southern and central basins. Kukui Canyon is cut into the delta and leads down to the deep part of the central basin (see Fig. 1, inset). CTD profiles measured in the canyon on 15 May 1995 (Fig. 6), just after the ice had disappeared from this part of the lake, show water at the bottom of the canyon with high salinity, increased turbidity (low light transmis- sion), and enhanced oxygen concentration. Water with similar characteristics was found at the southern slope of the delta. Measurements at position S2 (see Fig. 1) on 31 May 1995 show a layer of intruding water at 790-m depth with increased salinity and turbidity (Fig. 7). Similar structures were found on 25 June 1993.

In the southern basin the intruding water is slightly warmer than the ambient water (Fig. 7), while the bottom water in Kukui Canyon is significantly colder than the ambient water (Fig. 6). In fact, the temperature measured at the bottom of position $\mathrm{K} 2\left(T=3.07^{\circ} \mathrm{C}\right.$ at $\left.420 \mathrm{~m}\right)$ is the lowest ever registered below $300 \mathrm{~m}$ during any of our several cruises. High salinity and low light transmission are indicative of water from the Selenga. Both ionic salinity and concentrations of silicic acid are much higher in the inflow $\left(S_{c}=126\right.$ $\mathrm{mg} \mathrm{kg}{ }^{-1}$ [Votintsev 1993]; $S_{\mathrm{Si}}=12.5 \mathrm{mg} \mathrm{liter}^{-1}$ [L. Sigg unpubl. data]) than in the lake $\left(S_{c}=95.3 \mathrm{mg} \mathrm{kg}{ }^{-1} ; S_{\mathrm{Si}}=\right.$ $4.2 \mathrm{mg} \mathrm{liter}^{-1}$ [L. Sigg unpubl. data]).

The ionic salinity can be used to calculate the volume fraction, $\eta_{\text {mix }}$, of Selenga water in the river plume flowing along the canyon:

$$
\eta_{\operatorname{mix}}=\frac{S_{c, p}-S_{c, l}}{S_{c, r}-S_{c, l}}
$$

$S_{c, l}$ is the mean salinity of the lake water, $S_{c, r}$ the salinity of the river water, and $S_{c, p}$ the salinity measured in the river plume. At position $\mathrm{K} 2\left(S_{c, p}=107 \mathrm{mg} \mathrm{kg}^{-1}\right)$, the fraction of Selenga water is $\eta_{\text {mix }}=0.38$, and at $\mathrm{K} 3\left(S_{c, p}=100 \mathrm{mg} \mathrm{kg}^{-1}\right)$ it has dropped to $\eta_{\text {mix }}=0.15$. At position $\mathrm{K} 4$, the signal has become too weak to be able to evaluate Eq. 14.

Unfortunately, no corresponding data for $\mathrm{Si}(\mathrm{OH})_{4}$ exist. Thus, the above mixing ratios cannot be confirmed by an independent tracer. Because the temperature variations in the Selenga are too fast and not continuously recorded, it is not possible to check the mixing ratios by applying Eq. 14 to water temperature. However, the $\eta_{\text {mix }}$ values can be combined with the water temperatures measured in the plume $\left(\theta_{p}\right)$ and in the lake $\left(\theta_{l}\right)$ to estimate the temperature of the inflowing river $\left(\theta_{r}\right)$. If $\theta_{l}$ is approximated by the ambient water temperature at plume depth, the calculated river temperature becomes $\theta_{r} \approx 2.36^{\circ} \mathrm{C}$ with the values from $\mathrm{K} 2$ and $\theta_{r} \approx 2.18^{\circ} \mathrm{C}$ with the values from $\mathrm{K} 3$. Those temperatures drop if a larger value is chosen for $\theta_{t}$ (the river plume is flowing through the MTM where the ambient water is warmer!). In the middle of May 1995 surface temperatures were $\sim 2^{\circ} \mathrm{C}$ in the delta region and $1^{\circ} \mathrm{C}$ at the center of the central basin. Measurements by infrared satellites (D. LlewellynJones unpubl. data) confirm these values.

By comparing the density of a water parcel at variable depth $z, \hat{\rho}_{p a}\left(\theta_{p a}, S_{c, p a}, S_{\mathrm{S} i, p a}, z\right)$, with the in situ density, the depth can be calculated to which the parcel would sink by free convection if moved isentropically (see Eq. 13). Figure 8 shows $\Delta \hat{\rho}(z)$ calculated for two types of test parcels moved either to position $\mathrm{C} 1$ (central basin, dotted lines) or to $\mathrm{S} 1$ (southern basin, dashed lines). The first test parcel (bold lines) is taken from the bottom of Kukui Canyon at position $\mathrm{K} 2\left(\theta_{p a}=3.07^{\circ} \mathrm{C}, S_{c, p a}=107 \mathrm{mg} \mathrm{kg}^{-1}\right)$. The second parcel has the same salinity but is slightly warmer $\left(\theta_{p a}=3.5^{\circ} \mathrm{C}\right.$, thin lines). For both cases $S_{\mathrm{Si}, p a}$ was approximated by the 

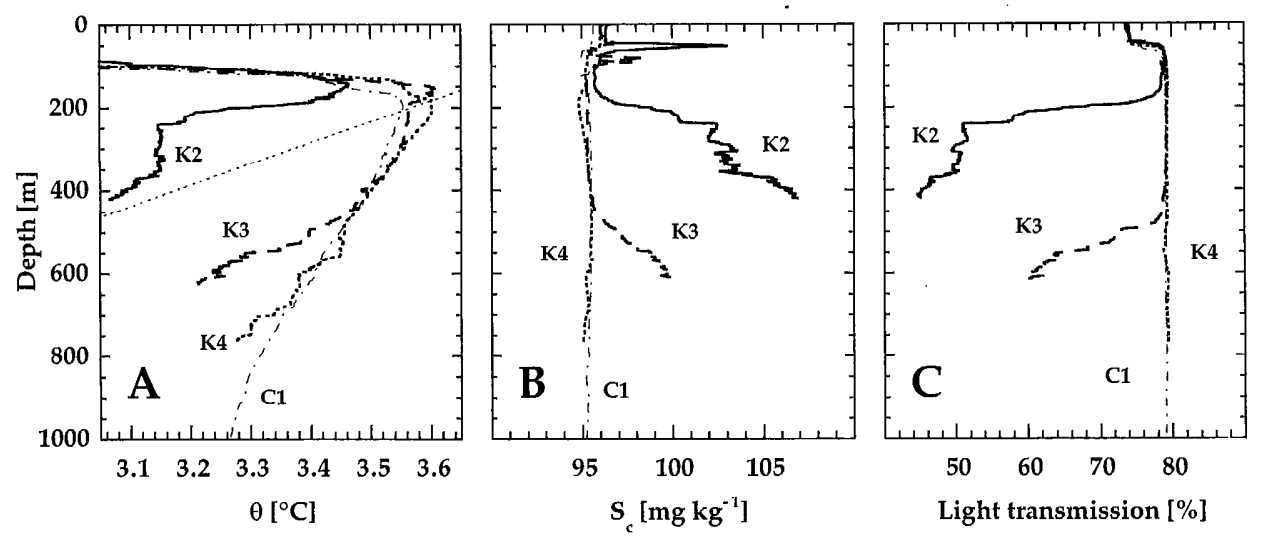

Fig. 6. (A) Potential temperature $\theta$, (B) ionic salinity $S_{c}$, and (C) light transmission in Kukui Canyon measured on 15 May 1995. See Fig. 1 for positions of stations. The profiles show cold water from Selenga with high salinity and turbidity (low light transmission) flowing along the bottom of the canyon. The bottom layer weakens with growing distance from the river mouth. At position $\mathrm{K} 2(-)$, located $\sim 12 \mathrm{~km}$ from the river mouth, the bottom water is colder than $T_{\mathrm{mos}}$. At $\mathrm{K} 3(---), 7 \mathrm{~km}$ farther along the canyon, the water is warmer than the local $T_{\mathrm{md}}$. At $\mathrm{K} 4(\cdots \cdots \cdots)$, $12 \mathrm{~km}$ north of $\mathrm{K} 3$, only a weak temperature signal remains. A profile measured at the deepest part of the central basin (C1) on 16 May 1995 is shown for comparison (-.-.-.-).

mean background $\mathrm{Si}(\mathrm{OH})_{4}$ concentration in the respective basin at $420 \mathrm{~m}$. The difference in $\mathrm{Si}(\mathrm{OH})_{4}$ concentrations between river and lake was neglected for calculating $\Delta \hat{\rho}(z)$, and the sinking depths are therefore slightly underestimated. According to Fig. 8, water from Kukui Canyon has the potential (i.e. if entrainment is negligible) of reaching the bottom of both the Central and Southern Basins. If water temperature is rising (e.g. in late spring when the Selenga becomes warmer) the plume would no longer reach the bottom of the basins. This process starts earlier in the Central than in the Southern Basin.

Two-dimensional isopleths of $\theta$ and $S_{c}$, shown in Fig. 9 for the conditions met in Kukui Canyon on 15 May 1995, confirm the conclusions drawn from Fig. 8. Selenga water flowing through the canyon is traced by its lower temperature and higher salinity. The neutral tracks shown in Fig. 9A (bold dashed lines) suggest that the bottom water from po- sition $\mathrm{K} 1$ and from position $\mathrm{K} 2$ moves along the canyon to the deep part of the basin. The neutral tracks give the direction of flow of a parcel that does not mix with ambient water. As shown above, mixing by entrainment is significant. Alternatively, the neutral surfaces (small sticks in Fig. 9A) represent the direction of flow of a water parcel that is continually being mixed with its environment. Because neutral tracks and neutral surfaces are fairly parallel to each other, the two complementary concepts define the rather narrow depth range within which Selenga water is expected to flow to the deep layers of the basins.

In spring 1993, when measurements started somewhat later in the year, the Selenga plume could be traced in the canyon to a depth of $\sim 700 \mathrm{~m}$. On 23 May 1993, a saline and slightly warmer lens of water could be identified $70 \mathrm{~km}$ north of the Selenga Delta at $1,000-\mathrm{m}$ depth in a section extending from the eastern shore of Boldakovo to the west-
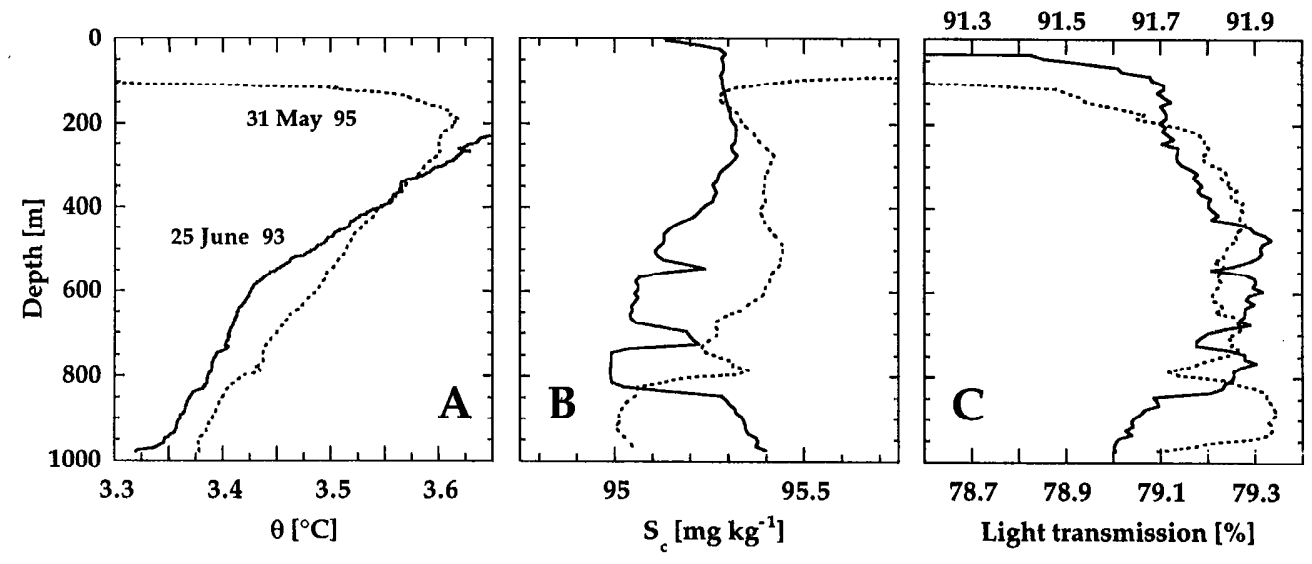

Fig. 7. (A) Potential temperature $\theta$, (B) ionic salinity $S_{c}$, and (C) light transmission measured at the southern slope of the Selenga Delta (position S2) on 25 June $1993(-)$ and on 31 May $1995(\cdots \cdots \cdots)$. 


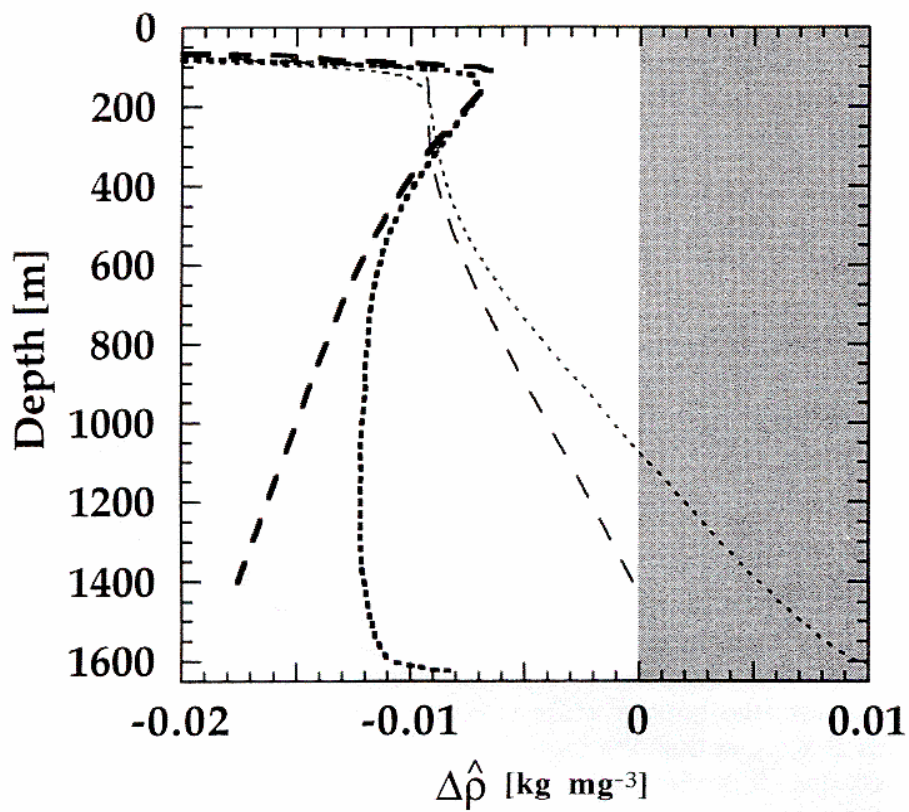

Fig. 8. Difference between in situ water density at position $\mathrm{C} 1$ (central basin, .......) or S1 (southern basin, - - -), respectively, and the density of a test parcel, $\hat{\rho}_{p a}\left(\theta_{p a}, S_{c, p a}, z\right)$, moved isentropically to these profiles (see Eq. 13). Bold lines: Test parcel from the bottom of Kukui Canyon at position $\mathrm{K} 2\left(\theta_{p a}=3.07^{\circ} \mathrm{C}, S_{c, p a}=107 \mathrm{mg}\right.$ $\left.\mathrm{kg}^{-1}\right)$. Thin lines: as before, but water temperature raised to $\theta_{p a}=$ $3.5^{\circ} \mathrm{C}$. Note that if entrainment is neglected, the parcel sinks through the water column as long as $\Delta \hat{\rho}(z)$ remains negative. Thus, for both temperatures the test parcel would reach the bottom of the southern basin. In the central basin it would be stopped at an intermediate depth if $\theta_{p a}$ were $3.5^{\circ} \mathrm{C}$.

ern shore of Olkhon Island (Fig. 10). The lens was also detected 3 weeks later, on 12 June. Based on observations made at the water surface (see below), we conclude that this water originates from the Selenga. According to the salinity signal, the fraction of Selenga water within the lens would be $\eta_{\text {mix }}=0.023$. If flowing at a mean speed of $3 \mathrm{~cm} \mathrm{~s}^{-1}$, it would take $\sim 4$ weeks for the river water to reach Boldakovo. Note that due to entrainment of warmer water from the MTM and due to the positive temperature gradient in the deep water of the basin, the lens is now warmer than the ambient water, in contrast to the observations made in the Kukui Canyon where the river plume is always colder.

In early June, the spring thermal bar (Shimaraev et al. 1993; Weiss et al. 1991) develops at Boldakovo and at other places along the eastern shore. At Boldakovo, the creation and movement of the thermal bar is controlled by the bottom topography and the northerly flow of warm Selenga water along the shore (Shimaraev et al. 1993). Chemical analysis of water samples taken from either side of the thermal bar and from the Selenga (L. Sigg unpubl. data) are applied to Eq. 14 to calculate the mixing ratio for the surface water trapped between the thermal bar and the shore (Table 3). Although the numbers for the different chemical components are not identical (how could they be, given all the uncertainties and the rather coarse resolution, e.g. for Sr?), they nonetheless give a fairly consistent picture, according to which between 20 and $50 \%$ (mean $=36 \pm 12 \%$ ) of the
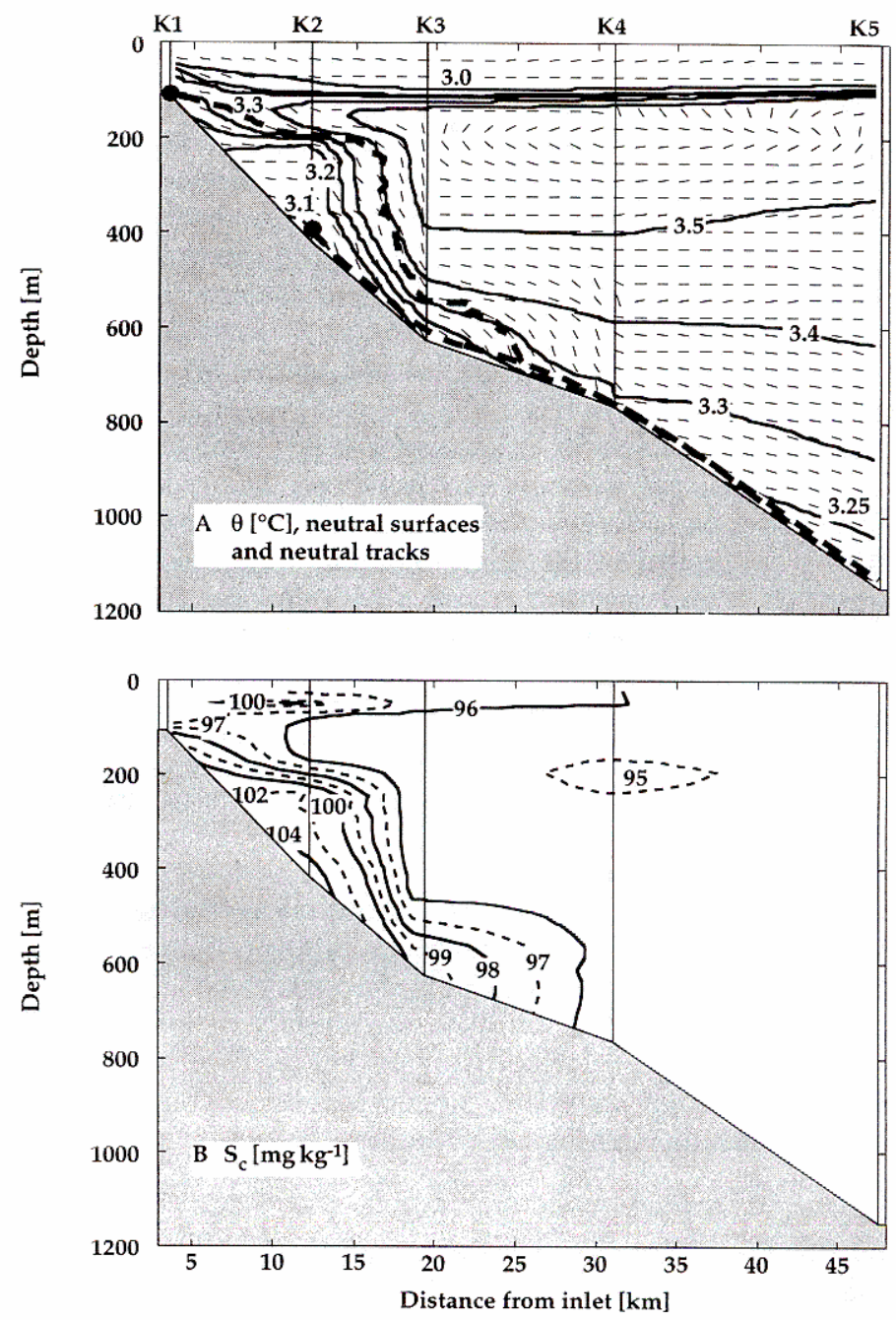

Fig. 9. Two-dimensional isopleths of (A) potential temperature $\theta$ and (B) ionic salinity $S_{c}$ measured along Kukui Canyon on 15 May 1995. Selenga water flowing through the canyon is traced by its lower temperature and larger salinity. The mesothermal temperature maximum (MTM) is poorly developed near the river mouth. The neutral track (A: bold dashed line) of a water parcel from the bottom at position $\mathrm{K} 1$ shows the potential of riverine water to penetrate through the MTM, although initially it does not flow along the bottom. The neutral track that starts at the bottom of position $\mathrm{K} 2$ follows the canyon. The neutral surfaces (small sticks), representing the direction of flow of a water parcel that is continuously mixed with its environment, are fairly parallel to the neutral tracks. Note that for the neutral tracks and neutral surfaces the influence of silica is included.

water along the shore originates from the Selenga. The ratio is significantly larger than that determined for the water lens detected at 1,000-m depth (Fig. 10). This indicates that entrainment of ambient lake water is greatly suppressed if the river water flows at the surface, trapped behind the thermal bar. Despite its high salinity, the water on the shore-side of the thermal bar is too warm ( $T>T_{\mathrm{md}}$ ) to sink to the bottom of the central basin. This was shown by Peeters et al. (1996) by using neutral tracks and neutral surfaces calculated from two-dimensional isopleths of $\theta$ and $S$ across the thermal bar at Boldakovo. 

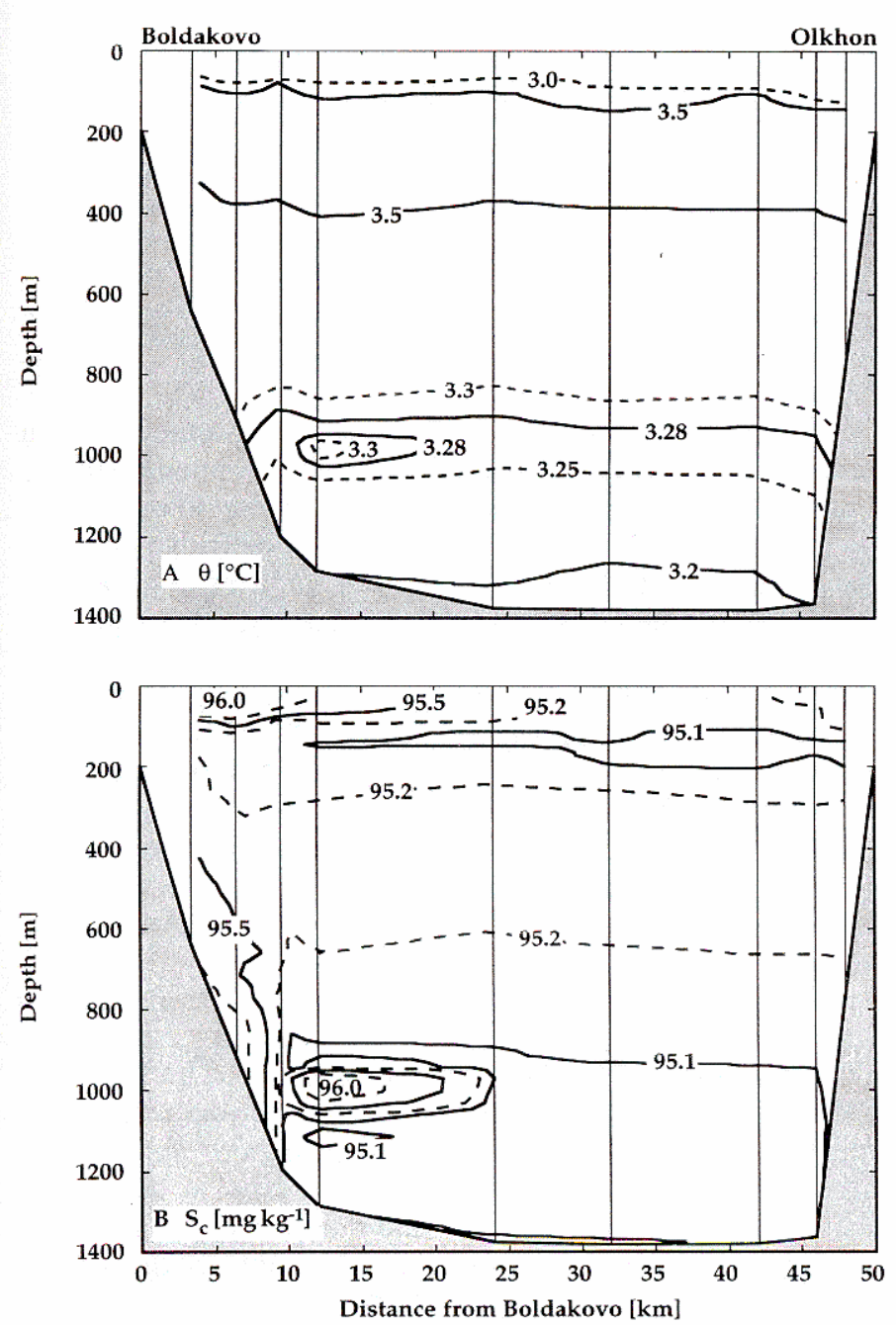

Fig. 10. Two-dimensional isopleths of (A) potential temperature $\theta$ and (B) ionic salinity $S_{c}$ along a transect between Boldakovo and Olkhon (see Fig. 1) measured on 23 May 1993. The isopleths show a lens of warm, saline water $12 \mathrm{~km}$ off the shore of Boldakovo at about $1,000 \mathrm{~m}$ depth. Based on salinity, the water within the lens contains about $2 \%$ Selenga water.

The observations presented in Figs. 6-10 can now be combined to yield a joint scenario of the likely sequence of events related to the Selenga. In spring, when, due to snow melting, the discharge of the Selenga increases from its typical winter mean value of $\sim 100 \mathrm{~m}^{3} \mathrm{~s}^{-1}$ to a monthly mean of $\sim 600 \mathrm{~m}^{3} \mathrm{~s}^{-1}$ in April and $1,700 \mathrm{~m}^{3} \mathrm{~s}^{-1}$ in May (Shimaraev et al. 1994), the water in the plume is cold and saline enough to flow along the lake floor to the bottom of the central basin and possibly to the bottom of the southern basin. On its way, it entrains significant quantities of lake water from different depths. This is reflected in the mixing ratio, which decreases from $\eta_{\text {mix }}=0.38$ at position $\mathrm{K} 2$ to $\eta_{\text {mix }}=0.15$ at position $\mathrm{K} 3$. Beyond $\mathrm{K} 3$, direct information on entrainment is lacking. However, other data can help to obtain a rough estimate of the final mixing ratio. First, for the lens at Boldakovo Fig. 10) a mixing ratio of $\eta_{\text {mix }}=0.023$ was determined. Second, by assuming that the salinity increase of $\sim 0.4 \mathrm{mg} \mathrm{kg}^{-1}$ measured at the bottom of the central basin (Figs. 2B, 4D) is
Table 3. Relative volume fraction $\eta_{\text {max }}$ of Selenga water in the water trapped between the thermal bar and the eastern shore of the central basin calculated from selected chemical data. $C_{C}, C_{S}$, and $C_{T B}$ are concentrations in the open surface water of the central basin, in the Selenga River, and in the water trapped behind the thermal bar at Boldakovo. Samples taken in June 1993 (L. Sigg unpubl. data).

\begin{tabular}{|c|c|c|c|c|}
\hline Parameter & $C_{C}$ & $C_{S}$ & $C_{T B}$ & $\eta_{\text {mix }}{ }^{*}$ \\
\hline Alkalinity $\left(\mathrm{mmol}\right.$ liter $\left.^{-1}\right)$ & 1.065 & 1.435 & 1.205 & 0.38 \\
\hline $\operatorname{Sr}\left(\mu \mathrm{mol}\right.$ liter $\left.^{-1}\right)$ & 1.5 & 1.975 & 1.6 & 0.21 \\
\hline $\mathrm{SO}_{4}^{2-}\left(\mathrm{mmol}\right.$ liter $\left.^{-1}\right)$ & 0.056 & 0.083 & 0.065 & 0.35 \\
\hline $\mathrm{Cl}^{-}\left(\mathrm{mmol} \mathrm{liter}{ }^{-1}\right)$ & 0.0145 & 0.0375 & 0.026 & 0.50 \\
\hline
\end{tabular}

* $\eta_{\text {mix }}=\frac{C_{T B}-C_{C}}{C_{S}-C_{C}}$ volume fraction of Selenga water trapped behind thermal bar (Eq. 14).
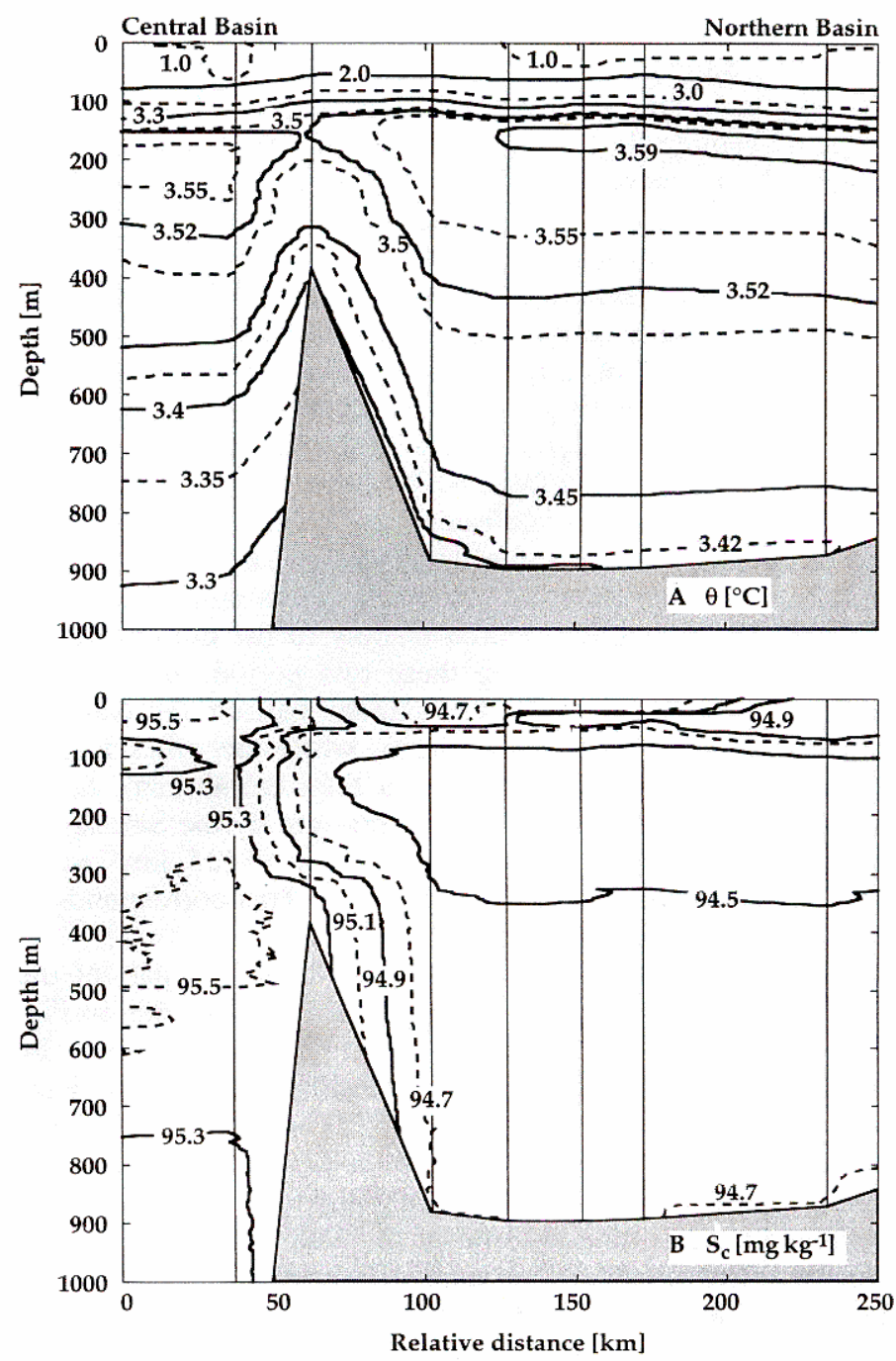

Fig. 11. Two-dimensional isopleths of (A) potential temperature $\theta$ and (B) ionic salinity $S_{c}$ along a transect across Academician Ridge from the central (left-hand side) to the northern basin (righthand side) measured on 22-24 May 1995 . The $3.42^{\circ} \mathrm{C}$ isotherm outlines the cold bottom boundary layer shown as the shaded area in Fig. 1. 
Table 4. Entrainment of ambient lake water into the Selenga River plume on its way to the deepest part of the central basin.

\begin{tabular}{|c|c|c|c|c|}
\hline & $\begin{array}{c}\text { Mixing } \\
\text { ratio } \\
\eta_{\text {mix }}(-)\end{array}$ & $\begin{array}{c}\text { Flow } \\
\left(\mathrm{m}^{3} \mathrm{~s}^{-1}\right)\end{array}$ & $\begin{array}{c}\text { Entrain- } \\
\text { ment } \\
\left(\mathrm{m}^{3} \mathrm{~s}^{-1}\right)\end{array}$ & $\begin{array}{c}\mathrm{CFC}-12^{*} \\
\left(\mathrm{pmol} \mathrm{kg}^{-1}\right)\end{array}$ \\
\hline Selenga $(0 \mathrm{~m})$ & 1 & $1,700 \dagger$ & - & $2.7 \neq$ \\
\hline $0-400 \mathrm{~m}$ & & & 2,800 & 2.7 \\
\hline $\mathrm{K} 2(400 \mathrm{~m})$ & 0.38 & 4,500 & & \\
\hline $400-600 \mathrm{~m}$ & & & 6,800 & 2.2 \\
\hline K3 $(600 \mathrm{~m})$ & 0.15 & 11,300 & & \\
\hline $600-1,500 \mathrm{~m}$ & & & 78,700 & 1.2 \\
\hline $\mathrm{C} 1(>1,500 \mathrm{~m})$ & 0.02 & 85,500 & & $1.32(1.35 \S)$ \\
\hline
\end{tabular}

* Volume-weighted CFC-12 concentrations in the corresponding depth zone determined from the vertical profile measured by Weiss et al. (1991).

$\uparrow$ Mean discharge of the Selenga in May (Shimaraev et al. 1994).

\# Assumed to be equal to the concentration at the lake surface.

$\$$ Calculated from the entrainment rates and the CFC- 12 concentrations measured in the upper part of the water column.

caused by Selenga water, one gets $\eta_{\text {mix }}$ of $\sim 0.013$. Both values point to a final mixing ratio lying between 1 and $3 \%$. In Table 4 absolute flow rates in the plume are summarized for a mean discharge rate of $1,700 \mathrm{~m}^{3} \mathrm{~s}^{-1}$ (typical value in May).

One way to check this scenario is to quantify its implications for the vertical transport of a conservative chemical such as CFC-12 (measured by Weiss et al. [1991]). The estimated flow rates in the plume and the measured volumeweighted mean concentrations of CFC-12 in the water column yield $1.35 \mathrm{pmol} \mathrm{kg}^{-1}$ for the concentration below 1,500 $\mathrm{m}$, which is in good agreement with the observed mean value of $1.32 \mathrm{pmol} \mathrm{kg}^{-1}$ (Table 4).

Based on the discharge rates and water temperatures of the Selenga we deduce that during April and about half of May, and during October, (1) discharge is significant, and (2) the water has the potential to flow to the bottom of the lake. Total discharge during these two periods is $\sim 5 \mathrm{~km}^{3}$. According to Votintsev (1993), about half of the Selenga water flows into the central basin, while the other half is diverted to the south. Assuming a final entrainment factor of 50 (Table 4), the water volume brought by the Selenga to the central basin $\left(2.5 \mathrm{~km}^{3}\right)$ increases to $\sim 125 \mathrm{~km}^{3}$ while flowing to the deepest part of the basin. This corresponds to the volume of the basin below $1,500 \mathrm{~m}$.

A similar behavior is to be expected for that part of the Selenga that flows into the southern basin. According to Fig. 8 the potential of the riverine water to sink here may be even slightly larger than in the central basin. Measurements by infrared satellites in late May (D. Llewellyn-Jones unpubl. data) show that Selenga water also flows southward along the eastern coast. The intrusions detected in the CTD profiles at the southern slope of the Selenga Delta (Fig. 7) can be interpreted as a mixture of water from the Selenga and from the lake, which sinks to the deeper parts of the basin. However, in contrast to the central basin, so far we have not been able to detect directly a plunging plume here.

Academician Ridge-At Academician Ridge, water masses with different $\theta$ and $S_{c}$ characteristics meet (Fig. 11). Below $50 \mathrm{~m}$, temperature is generally lower in the central basin than in the northern basin. The MTM is warmer and shal- lower in the northern basin $\left(3.59^{\circ} \mathrm{C}\right.$ at about $160-\mathrm{m}$ depth) than in the central basin $\left(3.55^{\circ} \mathrm{C}, 220 \mathrm{~m}\right)$. Below the MTM the horizontal temperature difference across the ridge increases to about $0.1 \mathrm{~K}$. Salinity is $\sim 1 \mathrm{mg} \mathrm{kg}^{-1}$ greater in the central basin than in the northern basin, because this basin receives the saline water from the Selenga, while the northern basin is chemically diluted by water from the Upper Angara, which has a salinity of $S_{c}=81 \mathrm{mg} \mathrm{kg}^{-1}$ (Votintsev 1993). The horizontal salinity gradient between these basins results in vertical isohalines near the ridge.

Between 23 May and 28 May 1995, water temperature in the lowest $10-20 \mathrm{~m}$ of the northern basin dropped distinctly by $0.03-0.05 \mathrm{~K}$. The cold bottom layer extended over a distance of about $200 \mathrm{~km}$ from Academician Ridge to $55^{\circ} \mathrm{N}$ (shaded area in Fig. 1). It covered an area of $\sim 4,000 \mathrm{~km}^{2}$ and had a volume of $40-80 \mathrm{~km}^{3}$. The cold bottom water was enriched with oxygen, which indicates that it must originate from above the MTM. A pronounced temperature decrease was also detected in spring 1993 (Fig. 4E). However, at this time the cold temperature signal was only found in the deepest part of the basin.

All attempts to find the cold bottom layer (characterised by $\theta<3.42^{\circ} \mathrm{C}$ ) north of $55^{\circ} \mathrm{N}$ failed. There is no indication that it is established by water from the Upper Angara, because the latter would produce a negative salinity signal. Yet, the $3.42^{\circ} \mathrm{C}$ isotherm extends southward and even rises to Academician Ridge. The temperature at the sill crest (depth $300 \mathrm{~m}$ ) is equal to the temperature of the cold bottom layer in the northern basin. The isotherms suggest that water with a temperature of $3.40^{\circ} \mathrm{C}$ flows down on both sides of the ridge to the deep part of the lake. Whereas in the central basin the cold water reaches only intermediate depths of about $600 \mathrm{~m}$, in the northern basin it sinks all the way to the bottom. Thus, Academician Ridge is a source of the cold deep water found in the northern basin.

Measurements along a short transect recorded on 23 May 1995 give a closer view of the stratification at the ridge (Fig. 12). The water column on the sill (position A2) is influenced by water from both the central and northern basins. The isohalines and isotherms reveal a complex structure of interleaving layers of different temperature and salinity. At the ridgc, a lens of cold water $\left(T=3.475^{\circ} \mathrm{C}\right)$ with a salinity of $95 \mathrm{mg} \mathrm{kg}^{-1}$ causes the MTM (bounded by the $3.52^{\circ} \mathrm{C}$ isotherm) to sink to 270-m depth.

The neutral tracks of different water parcels across Academician Ridge are shown in Fig. 13. The track of a parcel from position $\Lambda 1$ at $126-\mathrm{m}$ depth follows the $3.475^{\circ} \mathrm{C}$ isotherm to position $\mathrm{A} 2$, indicating that its direction is determined mainly by temperature (Peeters et al. 1996). At position A2, the track sinks to the lens of cold water at $160 \mathrm{~m}$ bounded by the $3.475^{\circ} \mathrm{C}$ isotherm. It then continues along the 94.6- $\mathrm{mg} \mathrm{kg}^{-1}$ isohaline, suggesting that close to the MTM its direction is dominated by salinity. The track then becomes unstable, i.e. it turns south and then north again. Thus, a parcel moving along this track drops from $230 \mathrm{~m}$ through the MTM to 330-m depth (see fig. 6 of Peeters et al. 1996). The track continues to sink to about $370-\mathrm{m}$ depth at position A3 and finally follows the isotherms to the deep part of the Northern Basin.

The neutral track of a parcel from 140-m depth at position 

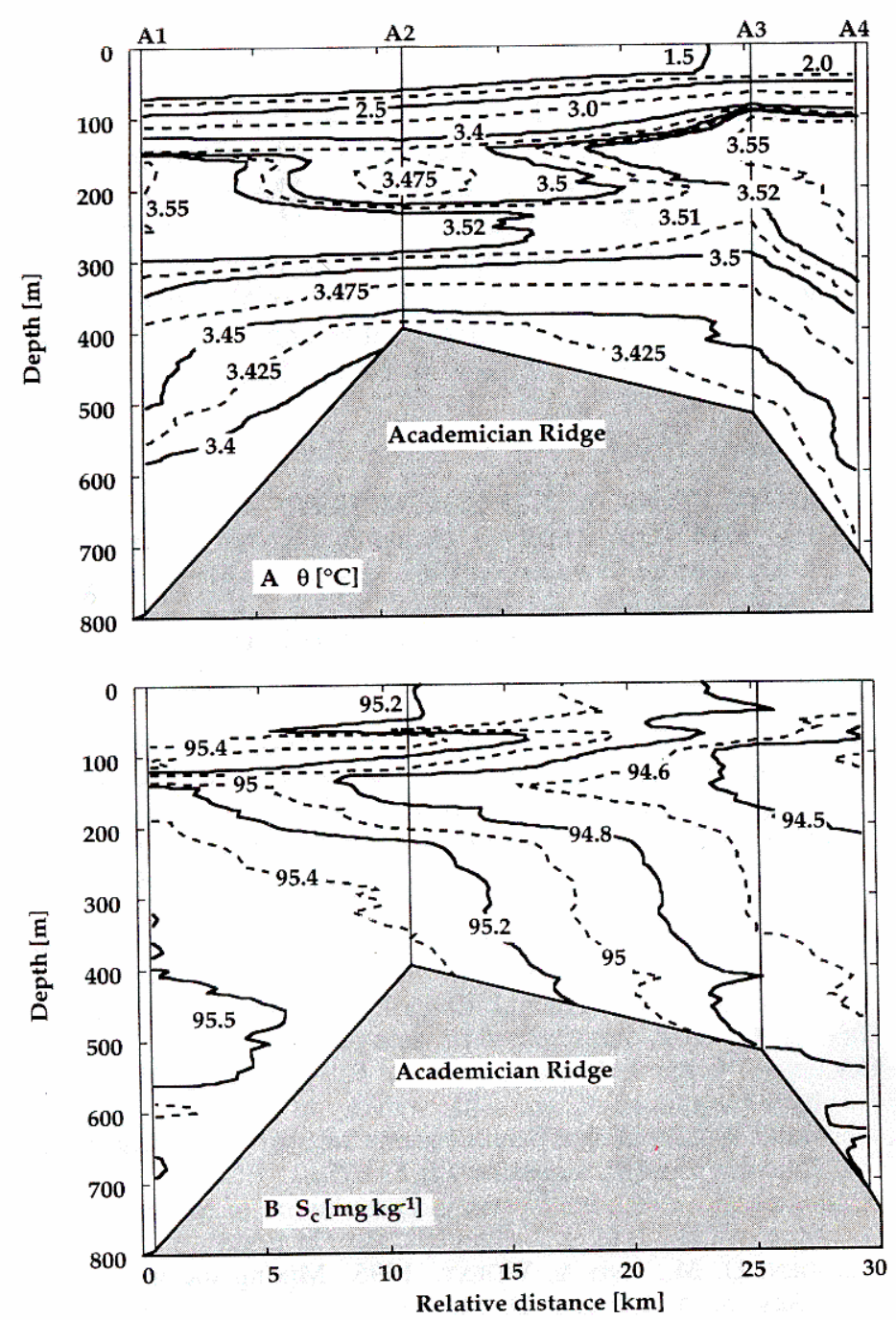

Fig. 12. Two-dimensional isopleths of (A) potential temperature $\theta$ and (B) ionic salinity $S_{c}$ along a short transect across the Academician Ridge measured on 23 May 1995. Isotherms and isohalines show interleaving water masses from both sides of the ridge.

A1 first takes a similar course. Beyond A2, the track becomes unstable and drops from $220 \mathrm{~m}$ through the MTM to 350-m depth. Below the MTM the neutral track continues along the bottom to the deep part of the northern basin. A third neutral track starting at $200 \mathrm{~m}$ at position A1 also sinks through the MTM to the deep part of the northern basin. Yet, due to the larger initial temperature, the track does not sink as deep as the tracks of the other parcels.

An additional track illustrates the path along which surface water from the northern basin can move buoyancy free across the ridge to the central basin. It leads from $100-\mathrm{m}$ depth at position $\mathrm{A} 3$ to $126 \mathrm{~m}$ at position A1. In contrast to the track of the upper parcel from position A1, it does not drop to the coldwater lens, but remains close to the $3.5^{\circ} \mathrm{C}$ isotherm at position $\mathrm{A} 2$.

Note that these results should not be overinterpreted. In fact, the bottom topography and the horizontal resolution of the measurements determine the course of the neutral tracks to a great extent. For instance, imagine that position A2 was

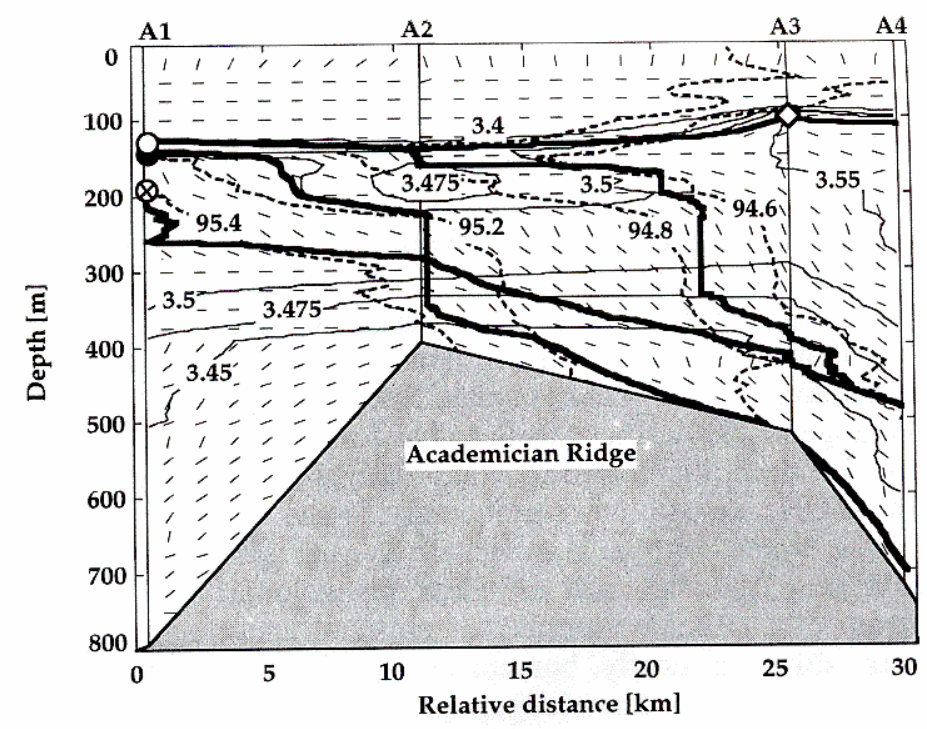

Fig. 13. Neutral tracks (thick solid lines) and neutral surfaces (sticks) across the Academician Ridge calculated for the situation encountered on 23 May 1995. The symbols mark the initial position of four different neutral tracks. Some isotherms and isohalines from Fig. 13 are included.

located at the southern slope rather than at the top of the sill. Then the neutral track from $140 \mathrm{~m}$ would hit the bottom south of the sill and sink into the central basin. Thus, the above discussion is meant to demonstrate the very special situation existing at the sill and the potential for the flow of water from the sill into both basins. Furthermore, one should remember that the concept of neutral tracks is based on the assumption that the parcel does not mix with the surrounding water. In contrast to this, the neutral surfaces describe the displacement of water that always mixes totally with its environment. At Academician Ridge both neutral tracks and neutral surfaces are nearly parallel. Both concepts suggest that water from above the MTM of the central basin is capable of sinking into the deep part of the northern basin. From the data it seems that deep-water formation takes place over a wide area of Academician Ridge. However, based on the available data a precise quantification of the overflow is not possible.

Six days later, on 29 May 1995, the situation encountered at Academician Ridge was practically the same as the one shown in Figs. 12 and 13. Neutral tracks calculated for water parcels from between 125 - and $200-\mathrm{m}$ depth at position A1 sink to the deep part of the northern basin. In 1993, when measurements started later in the year, surface temperatures at the ridge were already $3.4-3.6^{\circ} \mathrm{C}$. On 20 June 1993 , neutral tracks calculated for water parcels at the central basin side of the sill between 150 - and $200-\mathrm{m}$ depth still sink below the MTM of the northern basin but stay at $450-550-\mathrm{m}$ depth.

There is no indication of a similar process taking place at the sill between the southern and central basins. The salinity difference between the basins is too small to cause a significant density difference. Therefore, water from one side of the sill is not able to penetrate through the thermocline on the other side. Furthermore, horizontal stratification of the 
water column in the delta region is dominated by water from the Selenga.

\section{Conclusions}

The physics of Lake Baikal is unique in several respects. The lake is the deepest body of freshwater on earth. Except for the top $100 \mathrm{~m}$, temperatures are always close to the in situ temperature of maximum density, and thus the thermal expansivity of the water is small. Salinity is small and rather homogeneous, despite the fact that it differs by a factor of two between the major inflows. Finally, the vertical gradient of $\mathrm{Si}(\mathrm{OH})_{4}$ contributes significantly to the vertical stability of the water column. As a result, density variations in the lake are extremely small and three-dimensional. They are the result of a delicate interplay of physical and chemical factors, although mostly, but not always, the variation in $\theta$ is dominant. To our knowledge, only in Crater Lake (Oregon) are similar conditions found (McManus et al. 1993).

Based on the concept of neutral tracks developed by Peeters et al. (1996) and an extensive set of CTD profiles, we were able to identify the conditions and mechanisms of deep-water exchange. This process takes place where water masses with different properties meet horizontally. Although it would be premature to say that all such locations and time periods were found, we think that two important sites have been identified: (1) the Selenga Delta and Kukui Canyon leading from the delta into the central basin; and (2) Academician Ridge, separating the central and northern basins.

Important characteristics of the Selenga are its relatively high salinity and its large annual variation in discharge rate and water temperature. The latter leaves a short time slot in April and early May when the river water is not yet too warm and discharge is already large enough to form a plume that sinks to the deepest part of the central basin. Semiquantitative estimates of the total mass flow per year confirm that the process described is in good agreement with observations of tracers such as CFC-12. A similar process is likely to occur in the southern basin but has not been observed so far.

Deep-water formation at Academician Ridge is triggered by the small salinity difference between the central and northern basins, which, in turn, reflects the salinity difference in the major inflows to these basins. Here the fluxes are more difficult to quantify as long as measurements with higher spatial and temporal resolution are missing.

In Lake Baikal, annual exchange of water and salt is very small compared to the large volume of water. Therefore, spectacular changes in the physical and chemical characteristics of the lake are not to be expected. It is also very difficult to detect small residual fluxes in the total salt balance on a year-to-year basis. At present, it is not clear whether the salinity budget of the lake is balanced. Given the extreme sensitivity of deep-water mixing with respect to the salinity gradients in the lake, it is easy to see that vertical mixing may be strongly influenced by possible long-term changes in the salinity of Lake Baikal. Once confirmed by measurements in the lake, such changes are difficult to stop and reverse within a short time. Therefore, in order to protect this unique body of water, methods have to be developed to anticipate possible harmful changes in Lake Baikal.

With respect to vertical mixing and oxygen distribution two things are important: (1) continuous monitoring of Baikal's major inflows to detect possible changes in the salt balance of the lake; and (2) collection of more information on the physicochemical propertics of the water body. Unless a policy is adapted to monitor the lake in this way, developments that may lead to irreversible changes in this very special ecosystem may be identified too late.

\section{References}

Aeschbach-Hertig, W., R. Kipfer, M. Hofer, and D. M. ImbodEN. 1996. Density-driven exchange between the basins of Lake Lucerne (Switzerland) traced with the ${ }^{3} \mathrm{H}-{ }^{3} \mathrm{He}$ method. Limnol. Oceanogr. 41: 707-721.

Bradshaw, A., AND K. E. Schleicher. 1965. The effect of pressure on the electrical conductance of sea water. Deep-Sea Res. 12: $151-162$.

Chen, C. T., And F. J. Millero. 1986. Precise thermodynamic properties for natural waters covering only the limnological range. Limnol. Oceanogr. 31: 657-662.

Dickson, R. R., E. M. Gmitrowicz, and A. J. Watson. 1990. Deep-water renewal in the northern North Atlantic. Nature 344: $848-850$.

Falkner, K. K., C. I. Measures, S. E. Herbei.in, J. M. Edmond, AND R. F. WEISS. 1991. The major and minor element geochemistry of Lake Baikal. Limnol. Oceanogr. 36: 413-423.

Gill, A. E. 1982. Atmosphere-ocean dynamics. Academic.

Golubev, V. A., J. Klerkx, AND R. Kipfer. 1993. Heat flow, hydrothermal vents and static stability of discharging thermal water in Lake Baikal (south-eastern Siberia). Bull. Cent. Rech. Explor.-Prod. Elf Aquitaine 17: 53-65.

HoHmanN, R., AND OTHERs. 1997. Distrubution of helium and tritium in Lake Baikal. J. Geophys. Res. In press.

IMBODEN, D. M., AND A. WÜEST. 1995. Mixing mechanisms in lakes. In A. Lerman, D. M. Imboden, and J. R. Gat [eds.]. Physics and chemistry of lakes. Springer Verlag.

Killworth, P. D., E. C. Carmack, R. F. Weiss, and R. Matear. 1996. Modeling deep-water renewal in Lake Baikal. Limnol. Oceanogr. 41: 1521-1538.

KIPFER, R. AND OTHERS. 1993. A subaquatic river in the northern part of Lake Baikal. Ann. Geophys. 11: C262.

$\longrightarrow$, AND OTHERS. 1996. Bottom-water formation due to hydrothermal activity in Frolikha Bay, Lake Baikal. Geochim. Cosmochim. Acta 60: 961-971.

MCDougall, T. J. 1984. The relative roles of diapycnal and isopycnal mixing on subsurface water mass conversion. J. Phys. Occanogr. 14: 1577-1589.

_. 1987a. Neutral surface. J. Phys. Oceanogr. 17: 19501964.

- 1987b. Thermobaricity, cabbeling and water mass convcrsion. J. Geophys. Res. 92: 5448-5464.

McManus, J., R. W. Collier, And J. Dymond. 1993. Mixing processes in Crater Lake, Oregon. J. Geophys. Res. 98: 1829518307.

Peeters, F., G. Piepke, R. Kipler, R. Hohmann, and D. M. IMBODEN. 1996. Description of stability and neutrally buoyant transport in freshwater lakes. Limnol. Oceanogr. 41: 17111724 .

Shimarıev, M. N., N. G. Granin, And A. A. Zhadanov. 1993. Deep ventilation of Lake Baikal waters due to spring thermal bars. Limnol. Oceanogr. 38: 1068-1072.

_ 
1994. Physical limnology of Lake Baikal: A review. Irkutsk, Okayama.

Votintsev, K. K. 1993. On the natural conditions of Lake Baikal in connection with the development of its water quality standard. Water Resour. Res. 20: 523-532.

Walker, S. J., AND R. G. WatTs. 1995. A threc-dimensional numcrical model of deep ventilation in temperate lakes. J. Geophys. Res. 100: 22711-22731.

Weiss, R. F., E. C. Carmack, And V. M. Koropalov. 1991. Deep- water renewal and biological production in Lake Baikal. Nature 349: $665-669$.

Wüest, A., G. Piefke, and J. D. Halfman. 1996. Combined effects of dissolved solids and temperature on the density stratification of Lake Malawi, 183-202. In T. C. Johnson and E. O. Odada [eds.], The limnology, climatology and paleoclimatology of the East African Lakes. Gordon and Breach.

Received: 29 May 1996 Accepted: 17 October 1996 